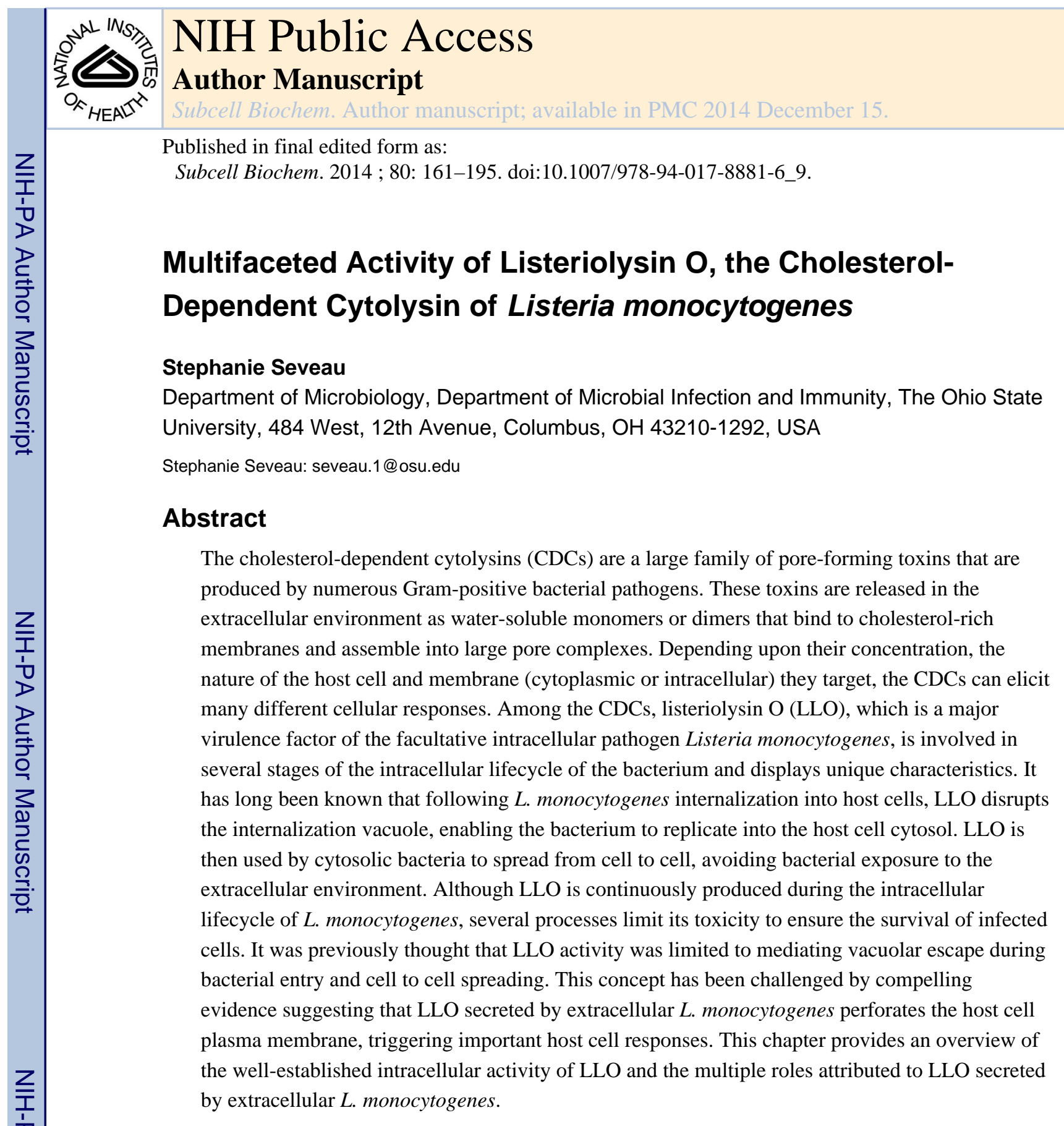

\title{
Keywords
}

Bacterial toxin; Cholesterol-dependent cytolysin; Infectious disease; Listeria monocytogenes; Listeriolysin $\mathrm{O}$

\section{Listeriolysin $\mathrm{O}$ is a Major Virulence Factor of L. monocytogenes Listeriosis}

The Gram-positive, facultative anaerobe Listeria monocytogenes is the causative agent of listeriosis, a life-threatening disease associated with a very high rate of mortality in humans

(C) Springer Science+Business Media Dordrecht 2014

Correspondence to: Stephanie Seveau, seveau. 1@osu. edu. 
(20-30 \%) and numerous other vertebrate species [1, 2]. This bacterium was isolated from diseased rabbits in 1926 by E. G. D. Murray and was recognized as the cause of a severe human foodborne illness in the early 1980s [3-5]. L. monocytogenes is ubiquitous in the environment, where it is found in soils, water, and plants, and frequently contaminates a large variety of raw and processed foods. The versatility of this organism comes from its ability to grow at a wide range of temperatures $\left(1-45^{\circ} \mathrm{C}\right)$ and $\mathrm{pH}(4.4-9.6)$, at high concentrations of salts (up to $10 \% \mathrm{NaCl}$ ), and to resist the harsh environment of the animal gut [6-9]. It is estimated that a brief intestinal carriage of L. monocytogenes, below 4 days, occurs at least twice a year in healthy adults [10]. Although healthy individuals typically remain asymptomatic, a self-limiting flu-like illness and gastroenteritis may develop [2, 11, 12]. L. monocytogenes is a greater concern for several high-risk populations, in brain, and placenta. The L. monocytogenes blood-brain or placental barriers [13-18]. In immunocompromised individuals, mainly the elderly, L. monocytogenes can cause bacteremia, meningitis, encephalitis, liver abscesses, and cardiac infections. Women are about twenty times more susceptible to listeriosis during pregnancy. While the mother may only exhibit mild symptoms, infection has devastating consequences for the developing fetus, resulting in miscarriages, preterm birth, still birth, or severe infection of the newborn [16]. Listeriosis is generally treated with ampicillin or amoxicillin, sometimes in combination with gentamicin [19]. However, late diagnosis combined with the immunodeficiency of the listeriosis patients and the high virulence of the bacterium likely explains the elevated rate of morbidity and mortality despite treatment [20].

\section{Listeriolysin O Plays a Critical Role in the L. monocytogenes Intracellular Lifecycle}

L. monocytogenes is a facultative intracellular pathogen that infects professional phagocytes and cells that are normally nonphagocytic in multiple organs: the intestines, spleen, liver, heart, brain, and placenta. The L. monocytogenes intra-cellular lifecycle is critical for pathogenesis since L. monocytogenes strains that are unable to infect host cells cannot cause disease. Major efforts have been devoted to the discovery of $L$. monocytogenes virulence factors and virulence mechanisms that orchestrate host cell invasion. Throughout the 1980s and 1990s, advancement of molecular biology techniques such as transposon mutagenesis, cloning, and sequencing led to the identification of a number of virulence genes. These genes are clustered on the Listeria Pathogenicity island-1 (LIPI-1) and the inlAB operon on the bacterial chromosome [21, 22]. Elucidating the role of these genes and discovering additional virulence genes is still the object of extensive studies [23, 24, 25].

The first step of the L. monocytogenes intracellular lifecycle is the entry of the pathogen into a host cell (Fig. 9.1). L. monocytogenes is phagocytosed with high efficiency by professional phagocytes, which express multiple phagocytic receptors such as complement, immunoglobulin, and scavenger receptors. This is in contrast to normally nonphagocytic cells that ingest $L$. monocytogenes with a lower efficiency. L. monocytogenes produces several virulence factors to promote its attachment to normally nonphagocytic cells and activate its internalization [26]. In particular, the surface proteins internalin (InlA) and InlB, encoded by the inlAB operon, specifically bind to their respective host cell receptors, E- 
cadherin and the hepatocyte growth factor receptor (HGF-Rc/c-Met) to stimulate $L$. monocytogenes internalization [27-34]. Following internalization into phagocytic or nonphagocytic cells, the bacterium is located into an endosome, called the primary vacuole. This vacuole is rapidly disrupted by the secreted pore-forming toxin listeriolysin O (LLO) encoded by hly on LIPI-1. LLO was initially identified as a hemolytic factor [35, 36], its role in host cell invasion was discovered later by performing electron microscopy analysis of macrophages and epithelial cells incubated with wild type or LLO-deficient $L$. monocytogenes. At an early stage of infection, wild type bacteria were located within a vacuole, and were then observed to proliferate in the cytosol. In contrast, L. monocytogenes strains in which hly was either interrupted by the insertion of a transposon or deleted, remained trapped in the vacuole, unable to divide [26, 37]. LLO-deficient bacteria were also nonvirulent in vivo, revealing the essential role of this toxin and the bacterial intracellular lifecycle in pathogenesis [37-41]. Additional studies showed that the L. monocytogenes surface protein ActA (encoded by actA on LIPI-1) is enriched at one pole of the bacterium, where it recruits the host cell F-actin polymerization machinery to generate a propulsive actin comet tail [42, 43]. F-actin polymerization randomly propels $L$. monocytogenes until it forms an extracellular protrusion that can invade an adjacent cell $[44,45]$. Once the adjacent cell has ingested the protrusion, L. monocytogenes is located into a secondary vacuole made of two membranes that originate from the donor and recipient cells. LLO is also required for the disruption of the secondary vacuole, releasing the bacterium into the cytosol of the newly infected cell. Cell-to-cell spreading is a very efficient process that propagates the bacterium within tissues, while avoiding exposure to the many antimicrobial molecules and phagocytes present in the extracellular environment $[46,47]$. In addition to LLO, two bacterial phospholipases, PI-PLC and PC-PLC respectively encoded by $p l c A$ and $p l c B$ on LIPI-1, facilitate L. monocytogenes escape from the primary and secondary vacuoles [48]. As further developed in the next paragraphs, recent studies suggest that LLO plays additional roles during the intracellular lifecycle of the bacterium. For example, LLO can also act as an invasin that stimulates $L$. monocytogenes internalization and affects the transcriptional activity of infected cells $[49,50]$.

\section{Regulation of Listeriolysin O Expression and Activity Listeriolysin 0 Expression}

Transcriptional regulation of $h l y$, the 1590-base pair gene coding for LLO, is predominantly controlled by the positive regulatory factor A (PrfA) [51-53]. PrfA binds to a 14-base pair palindromic sequence upstream of the promoter region to positively regulate the transcription of the major virulence genes of L. monocytogenes, which form the PrfA regulon [52, 54]. PrfA expression and activity are regulated at the transcriptional, translational, and post-translational levels [52]. Among the several factors that control PrfA expression or activity, temperature, carbon source, bacterial growth phase, and environmental stresses play an important role [55-57]. Of particular significance, the $\operatorname{prfA}$ mRNA functions as a thermosensor that selectively allows the translation of PrfA at $37{ }^{\circ} \mathrm{C}$ once the bacterium is within its animal host. The prfA mRNA $5^{\prime}$ untranslated region (UTR) adopts a hairpin structure that masks the ribosome binding site at temperatures below $30^{\circ} \mathrm{C}$, whereas this structure melts at the temperature of the host, $37^{\circ} \mathrm{C}$, leading to PrfA synthesis 
and transcription of $h l y$ and other virulence genes [58, 59]. Additionally, the hly promoter is more active when the bacterium is within host cells. This is independent of PrfA and requires the hly $5^{\prime}$ UTR, but the underlying mechanism remains unknown $[60,61]$. Finally, the $5^{\prime}$ coding region of the hly mRNA is also thought to control LLO translation in the cytosol [62].

The open reading frame of $h l y$ codes for a preprotein of 529 residues with an amino-terminal secretion signal sequence typical of those found in Gram-positive bacteria [63]. Upon secretion by the general secretory pathway, the signal sequence is cleaved by a signal peptidase releasing a mature protein of 504 residues. Due to the central role LLO plays during pathogenesis, molecular strategies preventing its synthesis, secretion, and/or activity are of great medical interest. For example, human antimicrobial peptides that belong to the $a$-defensin family, such as HNP1, prevent both LLO release by the bacterium and LLO activity via unknown mechanisms $[64,65]$. Once these mechanisms are solved, the development of defensin-like molecules could constitute promising therapeutic tools against L. monocytogenes and other CDC-producing pathogens [66].

\section{Mechanism of Assembly of the CDC Pore Complex}

LLO crystallization and X-ray crystallographic analysis were recently carried out; however, detailed structural determination is not yet established [67]. Structural information and models for pore formation are available for several other CDCs including PFO (perfringolysin $\mathrm{O}$, produced by Clostridium perfringens) [68, 69]. Based upon the high degree of identity between their amino acid sequences (28-99\%), CDCs likely share a similar three-dimensional organization into four domains (referred to as D1 to D4) (Fig. 9.2) and mechanism of pore formation [70-73]. These toxins are produced as water soluble monomers or dimers that bind to the lipid bilayer in an upright position through three hydrophobic loops-L1 to L3 - located at the base of the carboxy-terminal domain (D4) and form an oligomeric pore complex. It has been proposed that CDCs could form pores of different sizes [74]. In particular, studies using the patch-clamp technique or measuring the traversal of various membrane impermeant dyes across LLO pores, suggested that the size and/or shape of LLO pores formed in mammalian membranes could vary [75, 76]. However, the model for $\mathrm{CDC}$ pore formation that currently prevails proposes that CDCs assemble into a large ring-shaped pore oligomer. Whether there is some variation in size and/or shape of the pores among the CDC family members remain to be established.

Cholesterol is the receptor for most CDCs and plays an essential role in initiating the structural transitions required for formation of the pore complex [77, 78]. A threonineleucine pair conserved in all CDCs and located in L1, mediates direct binding of PFO, SLO (streptolysin O, secreted by Streptococcus pyogenes), and PLY (pneumolysin, produced by Streptococcus pneumoniae) to cholesterol [79]. We recently confirmed that the corresponding amino acid pair (Thr515/Leu516 in LLO) is required for LLO binding to cholesterol and pore formation (our unpublished observations). To date, cholesterol is the only known mammalian cell receptor for LLO, but the existence of additional lipid and/or protein receptors cannot be excluded [80, 81]. Also, preloading LLO with cholesterol does not abrogate its binding to biological membranes and a few CDCs utilize the surface protein 
CD59 as initial receptor before binding to cholesterol [81-84]. Following binding to cholesterol, the two proximal hydrophobic loops, L2 and L3, insert into the lipid bilayer. The undecapeptide signature sequence of CDCs -ECTGLAWEWWR- at the tip of D4, is then critical for stable monomer-monomer interactions, which transmit structural changes to D3, leading to the formation of stable prepore oligomers of 35-44 subunits [85]. During the prepore-to-pore transition, D3 $\alpha$-helices convert of into two amphipathic $\beta$-hairpins per toxin monomer, which insert across the lipid bilayer to form a $\beta$-barrel pore $[71,86,87]$.

Most studies on CDC structural remodeling during pore-formation have used PFO. For example, substitution of Gly57 and Ser190, (which are in close proximity in the folded protein) with cysteine residues generated an intramolecular disulfide bridge between D2 and D3. Formation of this disulfide bridge did not affect PFO binding to host membranes and oligomerization into a prepore complex, but halted structural rearrangements necessary for pore formation [88]. This construct allowed the authors to refine their model of CDC pore formation and establish that the rate-limiting step in the formation of the PFO pore is the assembly of the prepore complex and not the prepore-to-pore transition at the temperature of the animal host [88]. Importantly, amino acid substitutions at corresponding locations in LLO (G80C/S213C), determined by protein sequence alignment, also arrested LLO at the prepore stage [77, 89]. Also, amino acid substitution into cysteines at similar locations in LLO (K344C/I359C) and PFO blocked formation of the prepore complex in both toxins [88, 89]. Therefore, LLO and PFO adopt a similar fold and undergo similar intra- and intermolecular remodeling to form a pore complex.

\section{Regulation of LLO Activity by $\mathrm{pH}$, Oxidation, and Cholesterol}

Several physicochemical parameters control the formation of LLO pores, among which are the temperature and $\mathrm{pH}$ [35]. Indeed, the formation of LLO pores is $\mathrm{pH}$-sensitive at the temperature of the host $\left(37^{\circ} \mathrm{C}\right), \mathrm{LLO}$ being more active at acidic $\mathrm{pH}[90]$. Therefore, LLO activity is likely increased in acidic environments, such as the acidifying phagosome. The $\mathrm{pH}$ sensitivity of LLO is due to unfolding of the $\mathrm{D} 3$ transmembrane beta-hairpins at $37^{\circ} \mathrm{C}$ and neutral $\mathrm{pH}$ leading to LLO aggregation [91, 92]. Denaturation involves three acidic residues located in D3 (Asp208, Glu247, and Asp320) that act as a pH sensor. At neutral $\mathrm{pH}$, the combination of charge repulsions between acidic residues and thermal fluctuations leads to unfurling of the twin $\alpha$-helical bundles in D3, exposing hydrophobic residues and causing LLO aggregation [92]. Denaturation operates on a relatively long timescale, since it takes several minutes to inactivate LLO in physiological buffer at $37^{\circ} \mathrm{C}$ (at $\mathrm{pH} 7.4$ ) $[79,89]$. However, if bound to a lipid bilayer, LLO appears protected from denaturation and remains active [89]. The slow pH-dependent inactivation of LLO has two important biological implications. First, LLO secreted by extracellular L. monocytogenes can still perforate host cells at physiological temperature and neutral $\mathrm{pH}$, affecting the biology of the host cell from the extracellular compartment [80]. Second, the lifetime of LLO in extracellular fluids is limited, lessening its cytotoxicity $[49,89,93,94]$.

The efficiency of LLO pore formation also involves the amino acid Leu461, which exchange with a threonine generates a LLO variant that retains full activity at neutral $\mathrm{pH}$ [95]. This observation led to the initial conclusion that Leu461 was responsible for the $\mathrm{pH}-$ 
dependent activity of LLO. However, the LLO L461T variant was later shown to display similar rates of $\mathrm{pH}$ - and temperature-dependent denaturation, but an increased rate of hemolysis, suggesting that L461 rather controls the rate of LLO oligomerization [92].

CDCs were initially named the sulfhydryl-activated hemolysins for their ability to cause hemolysis in their reduced state, while they were inactive when oxidized [35]. Indeed, a unique cysteine in the undecapeptide sequence in $\mathrm{D} 4$ acts as a redox switch that turns off the activity of the oxidized toxin [35]. However, a cysteine-free LLO variant (LLO C484A) is still able to form pores, albeit with a lower efficiency [96]. The biological significance of this redox switch remains uncertain. A study proposed that $L$. monocytogenes exploits the gamma-interferon inducible lysosomal thiol reductase (GILT), located in lysosomes of antigen-presenting cells, to maintain LLO in its active reduced state [97].

It has also long been known that CDCs are inactivated by preloading with cholesterol prior to their binding to host membranes are inactive [35, 84]. This inactivation is attributed to premature and irreversible structural transitions in $\mathrm{D} 3$ of the CDC monomer. This property has been used as an experimental approach to establish the role of pore-formation in CDC activity. However, preloading CDCs with cholesterol raises several concerns. First, cholesterol insolubility in aqueous buffer may lead to uncontrolled formation of toxin/ cholesterol aggregates, decreasing toxin binding to host cells in addition to inhibiting pore formation. Also, the proportion of CDC associated to cholesterol is difficult to establish and some residual pore-forming activity may persist. As an alternative approach, amino acid variations in the LLO undecapeptide sequence were proposed to decrease the LLO poreforming activity; however it is unclear if binding and/or pore-formation are affected and these variants retain substantial capacity to form pores [96]. To unambiguously dissect the contribution of each stage of the LLO pore formation, i.e. binding as a monomer, formation of the prepore oligomer, and prepore-to-pore transition, in LLO function, two full length recombinant LLO variants were constructed (LLO monomer-locked and LLO-preporelocked). These variants retain the membrane binding capability of native LLO, but the LLO monomer-locked variant fails to oligomerize into a prepore complex, while the LLO prepore-locked variant forms a prepore complex that cannot undergo the prepore-to-pore conversion (Fig. 9.2) [89]. These variants are of great value to establish the structurefunction relationship of LLO.

\section{Listeriolysin $\mathrm{O}$ is an Intracellular Pore-Forming Toxin with Reduced Cytotoxicity}

\section{LLO Facilitates L. monocytogenes Escape from the Endocytic Vacuoles}

An essential function of LLO is to mediate L. monocytogenes escape from the primary and secondary vacuoles (Fig. 9.1). This activity is facilitated by three additional virulence factors: phosphatidylinositol-specific (PI-PLC) phospholipase, phosphatidylcholine-specific (PC-PLC) phospholipase, and a metalloprotease (Mpl) that activates PC-PLC, encoded respectively by $p l c A, p l c B$, and $m p l$ on LIPI-1 [90]. 
Escape from the Primary Vacuole-LLO is critical for L. monocytogenes escape from the primary endocytic vacuole in most cells, including professional phagocytes and nonphagocytic cells [26]. However, there are exceptions, since LLO-deficient $L$. monocytogenes can reach the cytosol of some nonphagocytic human cell lines [98]. In those cells, PC-PLC plays a major role in vacuolar escape in the absence of LLO $[99,100]$. On the contrary, in cells that require LLO for vacuolar escape, PI-PLC, but not PC-PLC, facilitates escape [48, 101]. Therefore, the process of vacuolar escape is controlled by both the $L$. monocytogenes virulence factors and host cells. The molecular basis for such variation in the mechanism of escape in different cell types or species is not yet understood. Also, how LLO alone or in cooperation with the bacterial phospholipases dismantles the primary endocytic vacuole is not fully explained. Many studies have addressed this question leading to multiple, non-mutually exclusive, hypotheses. Overall, LLO and the phospholipases delay the maturation of the vacuole and decrease its toxicity toward the bacterium, while compromising the integrity of the membrane. These virulence factors even affect host cell signaling before the bacterium is fully internalized. Indeed, extracellular LLO and PIPLC induce the translocation of the host protein kinase $\mathrm{C} \beta$ isoforms $(\mathrm{PKC} \beta)$ from the cytosol to endosomal membranes, which increases the efficiency of escape, possibly by altering endosomal recycling during early stages of phagosomal maturation [102]. The process of vacuolar escape takes $15-30 \mathrm{~min}$ in murine macrophages [76] and requires early maturation of the phagosome, such as its acidification and some low level of fusion with lysosomes. Phagosomal acidification may increase LLO pore-forming activity [95, 103]. Perforation of the phagosome by LLO then perturbs the intraphagosomal $\mathrm{pH}$ and calcium concentration, which in turn decreases the rate of phagosome fusion with lysosomes, giving time to the bacterium to fully disrupt the phagosomal membrane without being harmed by the toxic lysosomal contents [76, 104]. Indeed, LLO delays the acquisition of the late endosomal and lysosomal marker LAMP-1 [104]. The host thiol reductase GILT, which accumulates in the phagosome of macrophages, facilitates L. monocytogenes phagosomal escape in a cell culture model and is also important for L. monocytogenes virulence in mice. The direct role of GILT in maintaining LLO in its reduced active state is supported by the fact that purified GILT activates the hemolytic activity of recombinant LLO [97]. Beyond $\mathrm{Ca}^{2+}$ and $\mathrm{H}^{+}$ions, the intraphagosomal concentration of $\mathrm{Cl}^{-}$also affects the efficiency of vacuolar escape. Interestingly, the cystic fibrosis transmembrane conductance regulator (CFTR), which increases $\mathrm{Cl}^{-}$concentration in the phagosome, facilitates bacterial escape in vitro and potentiates L. monocytogenes virulence in mice [105]. This activity might be explained by the fact that high $\mathrm{Cl}^{-}$concentrations enhance the rate of LLO oligomerization, thereby facilitating pore-formation [105]. Recently, the L. monocytogenes PLCs were shown to stimulate the production of reactive oxygen species (ROS), which is unfavorable to $L$. monocytogenes intra-cellular survival. However, LLO counteracts this activity, importantly decreasing the toxicity of the phagosome [106]. When LLO and the phospholipases cooperate for escape, LLO may translocate the PLCs to grant them access to both sides of the lipid bilayer for more efficient digestion of their target phospholipids. A role for LLO in the translocation of the PLCs has not yet been shown, but another CDC, SLO was shown to translocate the virulence factor nicotinamide adenine dinucleotide-glycohydrolase into the host cell cytosol [107]. In conclusion, in addition to physical and biochemical damages inflicted to the phagosomal membrane, LLO and the PLCs also modify the maturation of the 
phagosome in multiple ways, which collectively leads to the release of the bacterium into the cytosol.

The Efficiency of Escape is Cell-Type Dependent and Varies with the Cell Activation State-L. monocytogenes does not escape from all phagosomes. The efficiency of escape depends upon the nature and activation status of the host cell, and can vary from phagosome to phagosome within the same cell. For example, LLO and the PLCs are less efficient in activated than resting macrophages and are unable to protect $L$. monocytogenes from intracellular killing in human neutrophils [108, 109]. In these examples, it appears that host cells can use various strategies to limit or even prevent vacuolar escape. These include exacerbated bactericidal activity of the phagosome, direct inhibition or degradation of LLO, or increased physical resistance of the endolysosomal compartment. In activated murine macrophages, the rapid production of reactive oxygen and nitrogen intermediates likely damage bacteria, limiting their ability to secrete the virulence factors required for escape [110]. Also, lysosomal cathepsin-D degrades LLO in murine fibroblasts and macrophages, limiting the efficiency of L. monocytogenes escape in cultured cells, and impacting the course of infection in a murine model of listeriosis [111]. A similar enzymatic process was recently proposed to exist in neutrophils in which the matrix metalloproteinase-8, stored in secondary granules, degrades LLO [109]. Also, the antimicrobial peptides, $\alpha$-defensins, stored at high concentrations in neutrophil primary granules, inhibit LLO release from the bacterium in addition to blocking its activity [64, 65]. Paradoxically, during L. monocytogenes phagocytosis by neutrophils, LLO triggers its own inactivation by stimulating the exocytosis of secondary and primary granules [109]. Finally, macrophage activation by multiple stimuli (TNF- $a$, peptidoglycan, etc.) diminishes the susceptibility of the phagosome and more generally, the endolysosomal network, to disruption by LLO and other stresses [112]. The molecular basis for this increased resistance of the endolysosomal network to multiple physical stressors remains to be elucidated. The process of autophagy also limits host cell invasion by targeting newly internalized bacteria that reside in damaged phagosomes $[113,114]$. LLO was shown to be necessary and sufficient to activate autophagy of the phagosome. However, the impact of autophagy varies with the nature of the infected cells: autophagy decreases infection of fibroblasts, but not of bone marrow derived macrophages [115]. It is important to highlight that autophagy does not affect $L$. monocytogenes growth in the cytosol since several bacterial factors prevent cytosolic recognition of the bacterium by the autophagy pathway (Fig. 9.1) $[113,114,116]$.

Escape from the Secondary Vacuole-The secretion of LLO, PI-PLC, and PC-PLC is also critical for L. monocytogenes escape from the secondary vacuole during cell-to-cell spreading $[46,48]$. To demonstrate the role of LLO in this process, LLO-deficient $L$. monocytogenes were noncovalently coated with recombinant LLO. This coating was sufficient to promote bacterial escape from the primary vacuole, allowing the bacterium to proliferate in the cytosol and undergo F-actin-based motility; however, bacteria were unable to escape from the secondary vacuole and failed to spread to adjacent cells [46]. Also, the construction of $L$. monocytogenes wild type and $p l c A / p l c B$ double deletion mutant strains that express hly under the control of an IPTG-inducible promoter, confirmed that both LLO and the PLCs are critical for L. monocytogenes escape from the secondary vacuole [117, 
118]. Electron microscopy analysis of infected macrophages showed that in the absence of continued LLO expression, but in the presence of the PLCs, L. monocytogenes remained predominantly trapped in secondary vacuoles made of one membrane. This observation indicates that the PLCs are critical for the disruption of the inner membrane (originating from the donor cell), whereas LLO is mostly involved in the disorganization of the outer membrane (originating from the recipient cell) [117]. Consistent with this model, when $L$. monocytogenes is transmitted to a recipient cell in which LLO was dispensable for the disruption of the primary vacuole, LLO was also dispensable for dissolution of the secondary vesicle [117].

\section{Mechanisms Reducing the Cytotoxicity of Listeriolysin 0}

In the cytosol, L. monocytogenes continuously produces LLO in order to spread from cell to cell [119]. L. monocytogenes tightly controls LLO synthesis and activity in order to disrupt vacuolar membranes without killing the infected cell. It has been well-established that $L$. monocytogenes mutant strains with increased LLO expression or activity escape from primary and secondary vacuoles, but are less virulent because they lyse the host cells, destroying their replicative niche [120,121]. Also, hly replacement by genes encoding other CDCs, such as PFO, ALO (anthrolysin O, produced by Bacillus anthracis), or ILY (intermedilysin O, produced by Streptococcus intermedius), under the control of the hly promoter, allowed L. monocytogenes vacuolar escape, but resulted in increased host cell lysis and loss of virulence in animal models [122-124]. Therefore, unlike other CDCs, LLO displays unique characteristics that limit its cytotoxicity. Additional studies revealed that the low cytotoxicity of LLO results from the combination of several processes including translational repression in the cytosol, $\mathrm{pH}$-dependent denaturation, and degradation by the proteasome.

pH-Dependent Denaturation of Listeriolysin O-LLO displays a relatively short lifetime in biological fluids and the cytosol, due to its propensity to aggregate at neutral $\mathrm{pH}$ (developed in section "Regulation of LLO Activity by $\mathrm{pH}$, Oxidation, and Cholesterol"). However, it should be noted that the pH-dependent denaturation of LLO does not instantaneously nor completely abrogate its activity. For example, intravenous injection of recombinant LLO in mice has multiple biological effects and can be lethal to the animal [35, 125]. Therefore, LLO has acquired additional features to decrease its cytotoxicity.

Listeriolysin O Expression and Degradation in the Cytosol-Sequence comparison between LLO and the more cytotoxic PFO revealed the presence of an additional region in the LLO N-terminal domain. Deletion of the corresponding DNA sequence from the L. monocytogenes genome increased LLO toxicity and severely decreased bacterial virulence. However, this deletion did not affect the efficiency of poreformation or vacuolar escape, indicating that the $\mathrm{N}$-terminal region does not control LLO activity $[120,126]$. This sequence contains eukaryotic PEST-like motifs (enriched in proline $(\mathrm{P})$, glutamic acid (D), aspartic acid (E) and serine (S) or threonine (T)), known to target proteins for degradation by the proteasome. Therefore, it was initially believed that the PEST-like sequences target LLO for degradation. Additional studies disproved this hypothesis. Even though LLO is phosphorylated and ubiquitinated within the PEST-like 
sequences and is degraded by the proteasome, LLO proteasomal degradation is independent of the PEST-like sequences. Furthermore, inhibition of the proteasome did not significantly affect the cytotoxicity of wild type L. monocytogenes [62]. It was then proposed that the $5^{\prime}$ coding sequence of the hly mRNA, corresponding to the N-terminal PEST-like sequences, negatively controls LLO translation in the cytosol [62]. Indeed, this sequence was shown to specifically decrease LLO synthesis during L. monocytogenes exponential growth in cell culture medium and in host cell cytosol [120]. When this sequence was inserted in the gene coding for PFO, PFO synthesis was also decreased [120]. Interestingly, when the PEST-like sequences were deleted, the resulting excess of cytosolic LLO was degraded by the proteasome, decreasing LLO cytotoxicity. Therefore, proteasomal degradation is an additional process that protects host cells in case of excessive production of LLO. LLO proteasomal degradation was proposed to involve the N-end rule pathway [127]. Finally, several hours post-infection, LLO was associated with numerous perinuclear aggregates of polyubiquitinated proteins in murine bone marrow derived macrophages [128]. The mechanism of formation and the fate of such LLO aggregates are unknown. It is possible that the $\mathrm{pH}$-dependent denaturation of LLO facilitates their formation. Also, such aggregates may sequester LLO and favor its subsequent degradation by the proteasome or the autophagy pathways. Formation of aggregates may represent an additional mechanism to reduce LLO cytosolic toxicity [128].

\section{Does Cytosolic Listeriolysin O Cause Organelle and/or Plasma Membrane Lesions?}

Mechanisms that decrease LLO concentration and activity in the cytosol are sufficient to ensure host cell survival; however, these mechanisms may not fully inhibit the activity of LLO in the cytosol. Moderate membrane damage caused by cytosolic LLO is likely difficult to observe, since host cells can undergo rapid repair of their organelles and plasma membrane. In favor of the idea that cytosolic LLO can target and perforate host cell membranes, it has been reported that, at late stages of cellular infection, a LLO-dependent $\mathrm{Ca}^{2+}$ rise is responsible for NF-kappa B activation and production of IL-6 [129]. The authors concluded that LLO released by L. monocytogenes in the cytosol damages the plasma membrane, leading to an influx of $\mathrm{Ca}^{2+}$, which activates cytokine production without killing infected cells [129]. Also, a more recent study suggested that LLO perforates the plasma membrane of bone marrow-derived macrophages at late stages of infection. Interestingly, the plasma membrane of caspase $7^{-/-}$macrophages was more damaged, revealing a role for this cysteine protease in maintaining the integrity of infected cells [130]. Therefore, LLO secreted into the cytosol may undergo moderate perforation of host cell membranes affecting the biology of infected cells. Such a process is likely to be detected at late stages of cell infection when the number of replicating bacteria is substantial. Studying LLO activity in the cytosol emerges as a relevant research focus. In this line of investigation, several points need to be clarified: (i) it is necessary to confirm that cytosolic LLO perforates host cell membranes and determine which membranes are preferentially targeted by LLO; (ii) establish if and how such membrane damage affects the course of infection; and if so, (iii) whether membrane damage favors the host or the pathogen. Finally, future studies will focus on elucidating the plasma membrane and organelle repair mechanisms, which are still poorly understood. 


\section{Listeriolysin $\mathrm{O}$ is an Extracellular Pore-Forming Toxin}

In addition to disrupting the primary and secondary vacuoles, LLO has been recently proposed to exert novel roles during the L. monocytogenes intracellular lifecycle. Indeed, a large body of evidence supports the idea that LLO secreted by extracellular $L$. monocytogenes perforates the host cell plasma membrane before bacterial entry, activating multiple signaling pathways. If cells are exposed to a moderate number of bacteria, the plasma membrane repair process maintains the integrity of the host cell. Nevertheless, the signaling activity of extracellular LLO modifies the biology of the host cell, potentially influencing the course of infection. Indeed, extracellular LLO was proposed to control $L$. monocytogenes internalization into nonphagocytic cells, vacuolar escape, organelle homeostasis, transcriptional activity, and the production of inflammatory mediators (Fig. 9.3). It is clear that we are only starting to appreciate the complexity and diversity of the activities of extracellular LLO.

\section{Listeriolysin O Released by Extracellular L. monocytogenes Activates Multiple Signaling Pathways}

Listeriolysin O Perforates the Host Cell Plasma Membrane-Extracellular $L$. monocytogenes perforates host cells in a LLO-dependent fashion. Perforation is indicated by a rapid, LLO-dependent influx of extracellular $\mathrm{Ca}^{2+}$ upon addition of $L$. monocytogenes to animal cells [75]. Cell perforation can also be directly detected by measuring the entry of small cell-impermeant fluorescent dyes into host cells, as for example ethidium homodimer or propidium iodide $[89,131]$. Plasma membrane perforation is a very dangerous situation for host cells, which must immediately eliminate the toxin pore in order to survive.

Host Cells Repair their Plasma Membrane-Animal cells are frequently wounded in tissues subjected to mechanical stress such as skeletal muscles, heart, intestine, lung, and skin. Mechanical lesions can span several micrometers and do not spontaneously reseal. The immediate consequence of membrane damage is a massive influx of extracellular $\mathrm{Ca}^{2+}$ into the cytosol, which is sensed as a membrane damage signal, triggering a complex multistep $\mathrm{Ca}^{2+}$-dependent membrane repair program [132-134]. Pore-forming proteins of the host immune system (perforin, complement membrane attack complex) or toxins produced by pathogens can also injure the host cell plasma membrane. Despite their relatively small size $(50 \mathrm{~nm}$ ), these transmembrane pores are very stable. If too many pores are formed, the target cell is rapidly lysed. However, active processes can restore the integrity of animal cells exposed to lower concentrations of toxins $[135,136]$. Recent studies proposed that host cells injured by the CDC SLO are repaired by $\mathrm{Ca}^{2+}$-dependent endocytosis of the toxin pores. The model for the repair of cells damaged by SLO shares some similarities with the repair model of large mechanical wounds. In this model, the influx of extracellular $\mathrm{Ca}^{2+}$ activates $\mathrm{Ca}^{2+}$-sensitive fusogenic proteins, such as the members of the SNARE family of proteins, inducing rapid lysosome fusion with the plasma membrane [137-139]. The exocytosed lysosomal enzyme acid sphingomyelinase (ASM) then converts sphingomyelin into ceramides on the outer leaflet of the plasma membrane. Ceramides were shown to induce inward curvature of the plasma membrane, which likely facilitates the endocytosis of SLO pores $[139,140]$. Once internalized, the toxin pores are trafficked to, and degraded 
within the lumen of multivesicular bodies [141]. Alternatively, other studies proposed that vesicles containing the SLO pores bud from the plasma membrane and are released in the extracellular compartment. This process is also activated upon $\mathrm{Ca}^{2+}$ influx and involves a family of $\mathrm{Ca}^{2+}$-regulated cytosolic proteins, the annexins [135, 142]. Resealing of the plasma membrane of cells exposed to low concentrations of LLO is $\mathrm{Ca}^{2+}$-dependent, but $\mathrm{K}^{+}-$, F-actin-, dynamin-, and clathrin-independent, which is compatible with the two proposed models [89]. Whether these two repair mechanisms coexist in a same cell, are cell type-dependent, or depend upon the extent of membrane damage remains to be elucidated. Also, it is possible that these models only incompletely describe the complex process of plasma membrane repair. Importantly, resealing of the plasma membrane may not always suffice to maintain cell viability. Indeed, if the rise in cytosolic $\mathrm{Ca}^{2+}$ is too high, a state of " $\mathrm{Ca}^{2+}$ overload" is reached, leading to the activation of cell death pathways despite recovery of the plasma membrane integrity [143].

Extracellular Listeriolysin $\mathbf{O}$ is a Potent Signaling Molecule-LLO signaling is not limited to the activation of the plasma membrane repair process. LLO activates multiple signaling pathways via two major mechanisms. First, similar to other CDCs, LLO is thought to bind to and reorganize cholesterol-rich microdomains, affecting the dynamics and signaling activities of these signaling platforms [144]. Second, CDCs form a large pore complex that measures $30-50 \mathrm{~nm}$, allowing ions and small molecules to diffuse across the plasma membrane, thereby eliciting multiple signaling events. For example, $\mathrm{Ca}^{2+}$ and $\mathrm{K}^{+}$ fluxes subsequent to cell perforation by LLO and other pore-forming toxins activate multiple pathways. Also, cell depolarization, $\mathrm{Na}^{+}$and $\mathrm{Cl}^{-}$perturbations, exposure to the oxidative extracellular environment, loss of ATP and small proteins, etc., all likely affect signaling.

The Versatility of $\mathrm{Ca}^{2+}$ and $\mathrm{K}^{+}$Signaling: Eukaryotic cells maintain a very low cytosolic concentration of $\mathrm{Ca}^{2+}(\sim 100 \mathrm{nM})$ in comparison to the extracellular environment $(\sim 1 \mathrm{mM})$. The endoplasmic reticulum (ER) and mitochondria also store $\mathrm{Ca}^{2+}$. This provides cells a means for rapid and sensitive signaling by increasing the cytosolic $\mathrm{Ca}^{2+}$ concentration through the activation of diverse channels and pumps on cytoplasmic and organelle membranes. $\mathrm{Ca}^{2+}$ is a universal second messenger that regulates a large array of cellular processes. How a cytosolic rise in $\mathrm{Ca}^{2+}$ controls many different pathways can be explained by the fact that cells integrate the amplitude, duration, pattern, and localization of the $\mathrm{Ca}^{2+}$ rises in any given cellular context. In the light of the central role $\mathrm{Ca}^{2+}$ plays, it is not surprising that pathogens have evolved to manipulate $\mathrm{Ca}^{2+}$ signaling. Upon interaction with host cells, LLO released by L. monocytogenes rapidly induces a rise in intracellular $\mathrm{Ca}^{2+}$, which was shown to result from: (1) $\mathrm{Ca}^{2+}$ influx across LLO pores and activation of $\mathrm{Ca}^{2+}$ channels at the plasma membrane; (2) release of $\mathrm{Ca}^{2+}$ from intracellular stores via PLCdependent activation of $\mathrm{Ca}^{2+}$ channels, (3) release of intracellular $\mathrm{Ca}^{2+}$ stores due to a direct insult of the ER [75, 145-148]. Many signaling pathways activated by extracellular LLO are linked to the rise in intracellular $\mathrm{Ca}^{2+}$. For example, a rise in intracellular $\mathrm{Ca}^{2+}$ affects $L$. monocytogenes internalization and organelle homeostasis. However, if the $\mathrm{Ca}^{2+}$ rise is too high, the situation of "calcium overload" can damage organelles such as the mitochondria and ER, potentially activating cell death pathways. 
Cells maintain a high intracellular concentration of $\mathrm{K}^{+}(\sim 140 \mathrm{mM})$ in comparison to the extracellular environment $(\sim 5 \mathrm{mM})$. The efflux of $\mathrm{K}^{+}$upon LLO perforation is also responsible for various cellular effects including activation of protein phosphorylation, autophagy, and transcriptional regulation [149]. Numerous $\mathrm{Ca}^{2+}$-sensitive transducers are known to respond to cytosolic variations in $\mathrm{Ca}^{2+}$ concentration; however, it is unclear how host cells sense and respond to variation in intracellular $\mathrm{K}^{+}$. Adding more complexity, the combinatorial effect of simultaneous ionic and molecular fluxes should be considered when studying how extracellular LLO controls host cell signaling [131].

Activation of MAPKs: LLO and many other pore-forming toxins are known to activate members of the large family of the mitogen-activated protein kinases (MAPKs) which include the extracellular signal-regulated kinase (ERK), p38, and Jun N-terminal kinase (JNK) subfamilies. These protein kinases transduce environmental and developmental signals into essential cell responses such as differentiation, apoptosis, and inflammation [150]. These kinases act through regulating transcription, but also exert more rapid effects that are independent of de novo protein synthesis. LLO is a potent activator of all three subfamilies, ERK1/2, p38, and JNK [149, 151]. Activation of ERK and p38 is independent of $\mathrm{Ca}^{2+}$ influx, but requires $\mathrm{K}^{+}$efflux [149]. Furthermore, ERK and p38 activation is important for recovering ion homeostasis following perforation by LLO [149]. Reflecting the diversity of events regulated by these transducers, it was reported that MEK-1/ERK2 is required for L. monocytogenes internalization into epithelial cells [151, 152].

SUMOylation: Another class of post-transcriptional modification more recently attributed to LLO is SUMOylation [93]. SUMO (Small Ubiquitin-like Modifier) is an ubiquitin-like polypeptide that can be covalently conjugated to proteins by three enzymes designated E1, E2, and E3. SUMOylation is reversible, as deSUMOylation proteases, the "deSUMOylases", cleave the SUMO group from the target protein. SUMOylation controls multiple cellular processes such as intracellular transport, transcriptional regulation, stress responses, cell cycle, and apoptosis [153, 154]. L. monocytogenes was shown to decrease the level of SUMOylated proteins in infected cells, in a LLO-dependent fashion [93]. This effect is due to the degradation of the unique human E2 enzyme, Ubc9, possibly via an aspartylprotease. Demonstrating the relevance of this pathway during pathogenesis, Ubc9 degradation was also observed in mice infected by L. monocytogenes [93]. As a consequence of Ubc9 degradation, there is an overall decrease in protein SUMOylation in $L$. monocytogenes infected cells. LLO alone, as well as other CDCs, is sufficient to exert this activity. Since increasing the global level of SUMOylated proteins by SUMO overexpression protects cells against $L$. monocytogenes infection, it was proposed that deSUMOylation subsequent to cell exposure to LLO favors pathogenesis. Which proteins are deSUMOylated during L. monocytogenes infection and how SUMOylated proteins protect host cells from infection remain to be established.

\title{
Roles of Extracellular Listeriolysin $\mathrm{O}$ in L. monocytogenes Internalization and Vacuolar Escape
}

\author{
Extracellular Listeriolysin $\mathrm{O}$ is Sufficient to Activate L. monocytogenes \\ Internalization-A particularity of L. monocytogenes is its ability to infect a large variety
}


of normally nonphagocytic cells. To invade nonphagocytic cells, bacterial surface adhesins anchor the bacterium to the host cell, while a second class of virulence factors, the invasins, activates the host cell internalization machineries. Some virulence factors can exert the dual function of adhesin and invasin. For example, InlA promotes both bacterial attachment and internalization by interacting with the cell adhesion molecule E-cadherin on epithelial cells. InlB only acts as an invasin by activating several receptors including HGF-Rc or c-Met [34]. L. monocytogenes uptake by normally nonphagocytic cells is poorly efficient when compared to professional phagocytes. Therefore, L. monocytogenes internalization into nonphagocytic cells is likely a limiting factor during pathogenesis. Thus, multiple adhesins and invasins may be required to facilitate L. monocytogenes internalization. Also with the wide range of cells L. monocytogenes infects, it is not surprising that this bacterium employs several adhesins and invasins to target diverse host cell receptors. It was reported that LLO alone can increase the efficiency of bacterial internalization into nonphagocytic cells, likely by mediating an influx of the second messenger $\mathrm{Ca}^{2+}$ [145]. It was shown more recently that LLO can act as an invasin, i.e. LLO is sufficient to induce the internalization of $L$.

monocytogenes into some nonphagocytic cell lines [89]. This study showed for the first time that a pore-forming toxin can activate bacterial internalization. This novel internalization pathway requires host cell tyrosine kinase activity, F-actin polymerization, dynamin, but is microtubule- and clathrin-independent [131]. The organization of the plasma membrane into signaling, cholesterol-rich microdomains is essential for L. monocytogenes internalization $[155,156]$. Thus, LLO binding to cholesterol-enriched microdomains may favor the creation a favorable signaling microenvironment. Furthermore, only native LLO, but not the LLO prepore-locked variant could induce bacterial internalization, revealing that formation of the LLO pore complex is strictly required for bacterial entry. This led to the hypothesis that membrane perforation is sufficient to activate F-actin remodeling and the host cell internalization machineries. In support of this, the CDC PLY also induces L. monocytogenes internalization and the parasite Trypanosoma cruzi was shown to perforate the host cell plasma membrane to stimulate its internalization [89, 157]. More recent studies propose that a combination of $\mathrm{Ca}^{2+}$ - influx and $\mathrm{K}^{+}$-efflux is required for the LLO-dependent internalization pathway. Further linking ion fluxes to bacterial internalization, cell treatment with both $\mathrm{Ca}^{2+}$ and $\mathrm{K}^{+}$ionophores, in the absence of LLO, could induce the internalization of large cargoes such as $1 \mu \mathrm{m}$ polystyrene beads or bacteria [131]. Thus, damaging the host cell plasma membrane emerges as an invasion strategy, shared by unrelated pathogens, that involves ion fluxes across the perforated plasma membrane. This invasion mechanism is relevant to many pathogens since pore-forming proteins are commonly produced by viruses, bacteria, and eukaryotic intracellular pathogens. The relationship between membrane perforation and pathogen internalization is certainly complex. Although some CDCs are required for uptake of Streptococcus and Listeria species, SLO exerts an anti-phagocytic activity for group A Streptococcus [89, 158, 159]. Additional studies are necessary to determine how membrane perforation can positively or, in some instances, negatively, regulate bacterial internalization.

\section{Extracellular Listeriolysin O Controls the Efficiency of Vacuolar Escape-It}

was proposed that host cell signaling activated by LLO before or during bacterial internalization influences subsequent vacuolar escape. Indeed, extracellular LLO and PI- 
PLC activate the translocation of PKC $\beta I I$ on endosomal membranes, which controls $L$. monocytogenes escape from the phagosome in murine macrophages [102]. Therefore, early signaling by extracellular LLO may importantly affect the composition and properties of the phagosome and the properties of the endosomal network that fuses with the phagosome. Further studies are necessary to better understand the role of extracellular LLO and PKC $\beta I I$ in endosomal trafficking and bacterial escape.

\section{Effects of Extracellular Listeriolysin $\mathrm{O}$ on Organelle Homeostasis and Transcription}

LLO secreted by L. monocytogenes in the extracellular compartment or recombinant LLO added exogenously to animal cells affect the ER and mitochondria. These effects result most likely from perforation of the plasma membrane, giving rise to an increase in intracellular $\mathrm{Ca}^{2+}$. Interestingly, it is proposed that the ER and mitochondria responses to LLO perforation then regulate positively or negatively host cell invasion.

Perturbation of the Endoplasmic Reticulum-The ER ensures essential cellular functions including posttranslational modification, folding, and sorting of newly synthesized proteins, lipid metabolism, and $\mathrm{Ca}^{2+}$ storage. In case of stress, the accumulation of unfolded proteins in the ER lumen is sensed by three ER-associated signal transducer proteins (PERK, ATF6, and IRE1) that activate the unfolded protein response (UPR). The UPR is conserved among all mammalian species and ensures cell survival until homeostasis is restored [160]. This response is characterized by a decrease in protein translation to limit the incoming pool of proteins in the ER, and by transcription of UPR target genes [161]. However, if the stress is too severe to be resolved, the UPR leads to apoptotic cell death [160]. Viral and bacterial pathogens have been shown to perturb ER homeostasis, activating the UPR. In particular, extracellular L. monocytogenes activates the UPR in a LLOdependent fashion and recombinant LLO, added exogenously to the cell culture medium, was sufficient to activate the UPR [162]. How LLO activates the UPR is not known. It can be speculated that LLO indirectly triggers this response via perturbation of $\mathrm{Ca}^{2+}$ homeostasis. Indeed, cell exposure to LLO leads to depletion of the $\mathrm{ER} \mathrm{Ca}^{2+}$ store, which is known to stimulate the UPR $[163,164]$. Apoptotic cell death via activation of the ERresident procaspase-12 upstream from the pro-apoptotic caspase- 3 was observed in a substantial proportion of cells infected with $L$. monocytogenes [162]. Cell treatment with UPR-activating chemicals before infection decreased the intracellular load of $L$. monocytogenes. Therefore, UPR activation can be considered as a host cell response that decreases L. monocytogenes infection and may lead to cell death, thereby destroying the bacterial replication niche [162]. Similarly, other studies on the pore-forming Crystal (Cry) produced by the invertebrate pathogen Bacillus thuringiensis have revealed that the UPR sensor IRE1, activated downstream from p38MAPK, protects Caenorhabditis elegans and mammalian cell lines against Cry toxins [165]. In addition to the UPR, other pathways likely control protein synthesis in cells exposed to pore-forming toxins, since recombinant LLO halted protein synthesis in a $\mathrm{K}^{+}$-dependent, but UPR-independent fashion [149]. This process was proposed to maintain the target cell in a quiescent state, while it recovers from toxin attack [149]. The ER is physically and functionally connected to the mitochondrial network [166]. It is therefore not surprising that pore forming toxins such as LLO affect the homeostasis of both ER and mitochondria. 
Transient Fragmentation of the Mitochondrial Network-Infection of epithelial cells by L. monocytogenes is paralleled with a transient fragmentation of the mitochondrial network [94]. LLO was identified as the virulence factor responsible for this effect, since recombinant LLO, but not LLO-deficient bacteria, induced mitochondrial fragmentation [94]. LLO also caused a loss of mitochondrial membrane potential and a decrease in respiration and cellular ATP. Mechanistically, these effects require an intact F-actin cytoskeleton and involve the ER rather than the canonical mitochondrial fission and fusion proteins Drp1 and Opa 1 [167]. Importantly, fragmentation of the mitochondrial network was transient and the cellular levels of ATP were recovered after a few hours [94]. The influx of extracellular $\mathrm{Ca}^{2+}$ was strictly required for mitochondrial fragmentation and recombinant LLO variants with lowered capacity to form pores were inactive, revealing the involvement of plasma membrane perforation by LLO in mitochondrial remodeling. Interestingly, this process was observed to be "all or nothing", which could reflects that a threshold level of LLO and subsequently of intracellular $\mathrm{Ca}^{2+}$ concentration is required [166]. Blocking mitochondrial remodeling could modulate the efficiency of $L$. monocytogenes invasion of host cells [94]. Mitochondrial fragmentation may maintain host cell viability by limiting an otherwise lethal $\mathrm{Ca}^{2+}$ overload since mitochondrial remodeling was not paralleled with apoptosis [94]. Such a protective response would advantage the bacterium by mediating host cell survival. It is also possible that L. monocytogenes affects the cell bioenergetics to favor infection.

\section{Roles of Extracellular Listeriolysin $\mathrm{O}$ in Inflammatory and Cell Death Pathways} Transcriptional Reprogramming via Histone Modifications-The DNA of all eukaryotic cells is wrapped around histone octamers made of two copies of each of four histones $\mathrm{H} 2 \mathrm{~A}, \mathrm{H} 2 \mathrm{~B}, \mathrm{H} 3$, and $\mathrm{H} 4$, forming nucleosomes. Posttranslational modifications of histones by acetylation, methylation, phosphorylation, or other modifications regulate gene expression, repair, replication, and recombination [168]. Pathogens also target histones in order to control the transcriptional activity of the infected host. LLO secreted by extracellular L. monocytogenes or recombinant LLO, but not LLO-deficient bacteria, induces the dephosphorylation of Ser10 on histone $\mathrm{H} 3$ and deacetylation of histone H4 [49]. Although it was initially thought that this function was independent of the formation of LLO pore complex, a more recent study by the same authors showed that this effect indeed results from an efflux of $\mathrm{K}^{+}$subsequent to LLO pore formation [169]. It was proposed that $L$. monocytogenes exploits histone modification to decrease the expression of some immunity genes, thereby lowering inflammation [49].

Activation of Innate and Adaptive Immunity_LLO affects the inflammatory response of the host through several processes. First, the toxin activates the inflammatory response by releasing $L$. monocytogenes into the cytosol, where the bacterium directly activates multiple NOD-like receptors (NLRs) [170-172]. Second, LLO alone released in the extracellular environment activates caspase- 1 and the transcription of inflammatory genes. More specifically, $\mathrm{K}^{+}$efflux subsequent to plasma membrane perforation by LLO or several other pore-forming toxins activates the NALP3 inflammasome leading to caspase-1dependent processing of pro-IL $1 \beta[169,173,174]$. Caspase- 1 was also shown to induce the translocation of the transcription factor SREBP to the nucleus, activating transcription of 
genes controlling lipid metabolism and cell survival [173, 175]. L. monocytogenes invasion of endothelial cells activates the pro-inflammatory transcription factor NF-KB and cytokine production in a LLO-dependent fashion [176]. Indeed, plasma membrane perforation by extracellular or intracellular LLO is responsible for NF- KB activation, surface expression of adhesion molecules, and the production of pro-inflammatory cytokines in epithelial cells $[129,176]$. It was also proposed that LLO and other CDCs activate Toll-like receptor 4, which then modulates the inflammatory response [177].

Additionally, LLO is an immunogenic protein that contains several T and B cells epitopes. Two CD4+ (corresponding to the amino acids 189-201 and 215-226) and one CD8+ (amino acids 91-99) immunodominant epitopes have been identified in LLO [178]. Thus LLO, which is indispensable for pathogenesis, will ultimately be used by the immuno-competent host to drive the activation of immune cells, permanently eliminating the pathogen. In addition to providing major antigens, LLO is an immunomodulatory molecule. Several highly promising anti-tumor vaccine candidates use LLO or LLO variants as adjuvants [178]. The molecular basis of the LLO adjuvant properties is still unclear, but highlights the key role LLO plays in the control of innate and adaptive immune responses. It is proposed that LLO immunomodulatory activities are independent of its poreforming activity [179].

\section{Activation of Cell Death Pathways by Extracellular Listeriolysin $0-L$.}

monocytogenes has long been known to cause rapid — one to three days post-infectionapoptotic lesions in the spleen, lymph nodes, brain, and liver of infected mice [180]. In the liver, lesions are associated with infected hepatocytes, suggesting that cellular infection is responsible for activating the cell death pathway [181]. Although L. monocytogenes can activate apoptosis in macrophages and dendritic cells, $\mathrm{T}$ lymphocytes is the predominant cell type involved in apoptotic lesions in vivo [180]. In the spleen, massive lesions containing apoptotic T lymphocytes were observed independently of the mouse and L. monocytogenes strains and route of infection $[125,180]$. Several lines of evidence strongly support that LLO secreted in the extracellular environment is responsible for lymphocyte apoptosis. First, apoptotic lymphocytes were not infected with $L$. monocytogenes, but free $L$. monocytogenes were observed in the affected areas. Thus, an extra-cellular factor such as LLO is likely responsible for apoptosis. Second, apoptosis was LLO-dependent, required LLO secretion, and could be induced in the draining lymph nodes following injection of recombinant LLO in the mouse footpads $[125,182]$. Lymphocyte apoptosis decreased with bacterial burden when LLO-neutralizing antibodies were injected in infected mice [183, 184]. Finally, in support of a direct role of LLO, sublytic concentrations of LLO induce lymphocyte apoptosis in vitro [125]. Indeed, LLO can activate caspase-dependent (rapid) and independent (slow) pathways leading to apoptosis. A rapid activation of capase-3, -6, and -9, was observed in cells treated with LLO and was followed by exposure of phosphatidylserine on the outer leaflet of the plasma membrane, mitochondrial depolarization, and DNA fragmentation [125]. Granzymes play a major role in LLO-induced T-cell apoptosis in vitro and in vivo [185]. LLO is likely endocytosed and acts intracellularly to disrupt the lytic granules, thereby releasing granzymes into the cytosol, where the enzymes activate apoptosis [185]. Importantly, it was shown that LLO facilitates the production of type I interferon, which sensitizes T lymphocytes to the apoptogenic function of LLO [186]. 
Apoptosis facilitates L. monocytogenes infection by decreasing host resistance and facilitating bacterial proliferation [187]. Thus the role of extracellular LLO in lymphocyte apoptosis is clearly characterized in vitro and in vivo. Importantly, this extracellular activity of LLO substantially affects the course of infection.

\section{Concluding Remarks}

LLO has emerged as a multifunctional toxin that regulates the intracellular life-cycle of $L$. monocytogenes in diverse cell types and affects the innate and adaptive immune responses. Many more studies are necessary to better delineate the mechanisms of action of this toxin. In particular, how LLO facilitates the disruption of the endocytic vacuoles containing $L$. monocytogenes is still unclear. LLO secreted by extracellular bacteria also targets and affects the biology of multiple cell types, from epithelial cells to $\mathrm{T}$ lymphocytes.

Extracellular LLO may control several stages of the L. monocytogenes intracellular lifecycle including bacterial internalization, vacuolar escape, and efficient intracellular replication. Extracellular LLO may also affect many cell types that the bacterium does not infect. For example, LLO can modulate the production of inflammatory messengers and cell death pathways independently of host cell invasion. A major challenge in the field is now to distinguish the extracellular from intracellular activities of LLO in vivo, and to determine which, if not all, of the host cell responses to LLO observed in cell culture models play a substantial role during pathogenesis. A fascinating aspect of LLO is its dual role during infection: whereas LLO is indispensable for pathogenesis, it is a major immunogenic molecule that ultimately elicits Listeria monocytogenes killing by the immunocompetent host. Due to its unique set of properties, LLO has emerged as a promising tool for the development of vaccine adjuvants. However, the molecular basis of the LLO immunomodulatory activity is poorly understood. Gaining knowledge on the interplay between LLO and host cells will importantly benefit basic research on pathogen-host interaction, pore-forming toxins, immunity, as well as the design of vaccines.

\section{Acknowledgments}

This work was made possible by Grant R01AI107250 (Stephanie Seveau) from the National Institutes of Health (NIAID) and its contents are solely the responsibility of the author and do not necessarily represent the official views of the NIAID.

\section{Abbreviations}

$\begin{array}{ll}\text { ALO } & \text { Anthrolysin O } \\ \text { ASM } & \text { Acid sphingomyelinase } \\ \text { CDC } & \text { Cholesterol-dependent cytolysin } \\ \text { CFTR } & \text { Cystic fibrosis transmembrane conductance regulator } \\ \text { ER } & \text { Endoplasmic reticulum } \\ \text { ERK } & \text { Extracellular-signal-regulated kinase } \\ \text { GILT } & \text { Gamma-interferon inducible lysosomal thiol reductase }\end{array}$




\begin{tabular}{ll} 
HGF & Hepatocyte growth factor receptor \\
HNP1 & Human neutrophil peptide \\
ILY & Intermedilysin O \\
InIA & Internalin A \\
InIB & Internalin B \\
IPTG & Isopropyl $\beta$-D-1-thiogalactopyranoside \\
JNK & C-Jun N-terminal kinase \\
LIPI-1 & Listeria pathogenicity island \\
LLO & Listeriolysin O \\
MAPK & Mitogen-activated protein kinase \\
MHC & Major histocompatibility complex \\
Mpl & Metalloprotease \\
NLRs & NOD-like receptors \\
PERK & Double-stranded RNA activated protein kinase (PKR)-like ER kinase \\
PC-PLC & Phosphatidylcholine-specific phospholipase \\
PI-PLC & Phosphatidylinositol-specific phospholipase \\
PFO & Perfringolysin O \\
PLY & Pneumolysin \\
PrfA & Positive regulatory factor A \\
ROS & Reactive oxygen species \\
SLO & Streptolysin O \\
SUMO & Small ubiquitin-like modifier \\
UPR & Unfolded protein response \\
UTR & Untranslated region \\
\hline
\end{tabular}

\section{References}

1. Oevermann A, Zurbriggen A, Vandevelde M. Rhombencephalitis caused by Listeria monocytogenes in humans and ruminants: a zoonosis on the rise? Interdiscip Perspect Infect Dis. 2010; 2010:632513. [PubMed: 20204066]

2. Swaminathan B, Gerner-Smidt P. The epidemiology of human listeriosis. Microbes Infect. 2007; 9:1236-1243. [PubMed: 17720602]

3. Linnan MJ, Mascola L, Lou XD, Goulet V, May S, Salminen C, Hird DW, Yonekura ML, Hayes P, Weaver R, et al. Epidemic listeriosis associated with Mexican-style cheese. N Engl J Med. 1988; 319:823-828. [PubMed: 3137471]

4. Murray EGD, Webb RA, HBRS. A disease of rabbits characterized by a large mononuclear leucoytosis caused by a hitherto undescribed bacillus Bacterium monocytogenes. J Pathol Bacteriol. $1926 ; 29: 407-439$. 
5. Schlech WF 3rd, Lavigne PM, Bortolussi RA, Allen AC, Haldane EV, Wort AJ, Hightower AW, Johnson SE, King SH, Nicholls ES, Broome CV. Epidemic listeriosis-evidence for transmission by food. N Engl J Med. 1983; 308:203-206. [PubMed: 6401354]

6. Barbuddhe SB, Chakraborty T. Listeria as an enteroinvasive gastrointestinal pathogen. Curr Top Microbiol Immunol. 2009; 337:173-195. [PubMed: 19812983]

7. Begley M, Gahan CG, Hill C. Bile stress response in Listeria monocytogenes LO28: adaptation, cross-protection, and identification of genetic loci involved in bile resistance. Appl Environ Microbiol. 2002; 68:6005-6012. [PubMed: 12450822]

8. Chaturongakul S, Raengpradub S, Wiedmann M, Boor KJ. Modulation of stress and virulence in Listeria monocytogenes. Trends Microbiol. 2008; 16:388-396. [PubMed: 18619843]

9. Dussurget O, Cabanes D, Dehoux P, Lecuit M, Buchrieser C, Glaser P, Cossart P. Listeria monocytogenes bile salt hydrolase is a PrfA-regulated virulence factor involved in the intestinal and hepatic phases of listeriosis. Mol Microbiol. 2002; 45:1095-1106. [PubMed: 12180927]

10. Grif K, Patscheider G, Dierich MP, Allerberger F. Incidence of fecal carriage of Listeria monocytogenes in three healthy volunteers: a one-year prospective stool survey. Eur J Clin Microbiol Infect Dis. 2003; 22:16-20. [PubMed: 12582739]

11. Ooi ST, Lorber B. Gastroenteritis due to Listeria monocytogenes. Clin Infect Dis. 2005; 40:13271332. [PubMed: 15825036]

12. Wing EJ, Gregory SH. Listeria monocytogenes: clinical and experimental update. J Infect Dis. 2002; 185:S18-S24. [PubMed: 11865436]

13. Alonzo F 3rd, Bobo LD, Skiest DJ, Freitag NE. Evidence for subpopulations of Listeria monocytogenes with enhanced invasion of cardiac cells. J Med Microbiol. 2011; 60:423-434. [PubMed: 21266727]

14. Disson O, Lecuit M. Targeting of the central nervous system by Listeria monocytogenes. Virulence. 2012; 3:213-221. [PubMed: 22460636]

15. Goulet V, Hebert M, Hedberg C, Laurent E, Vaillant V, De Valk H, Desenclos JC. Incidence of listeriosis and related mortality among groups at risk of acquiring listeriosis. Clin Infect Dis. 2012; 54:652-660. [PubMed: 22157172]

16. Poulsen KP, Czuprynski CJ. Pathogenesis of listeriosis during pregnancy. Anim Health Res Rev. 2013; 14:30-39. [PubMed: 23347534]

17. Ramaswamy V, Cresence VM, Rejitha JS, Lekshmi MU, Dharsana KS, Prasad SP, Vijila HM. Listeria-review of epidemiology and pathogenesis. J Microbiol Immunol Infect. 2007; 40:4-13. [PubMed: 17332901]

18. Robbins JR, Bakardjiev AI. Pathogens and the placental fortress. Curr Opin Microbiol. 2012; 15:36-43. [PubMed: 22169833]

19. Temple ME, Nahata MC. Treatment of listeriosis. Ann Pharmacother. 2000; 34(5):656-661. [PubMed: 10852095]

20. Le Monnier A, Abachin E, Beretti JL, Berche P, Kayal S. Diagnosis of Listeria monocytogenes meningoencephalitis by real-time PCR for the hly gene. J Clin Microbiol. 2011; 49:3917-3923. [PubMed: 21918022]

21. Vazquez-Boland JA, Dominguez-Bernal G, Gonzalez-Zorn B, Kreft J, Goebel W. Pathogenicity islands and virulence evolution in Listeria. Microbes Infect. 2001; 3:571-584. [PubMed: 11418331]

22. Vazquez-Boland JA, Kuhn M, Berche P, Chakraborty T, Dominguez-Bernal G, Goebel W, Gonzalez-Zorn B, Wehland J, Kreft J. Listeria pathogenesis and molecular virulence determinants. Clin Microbiol Rev. 2001; 14:584-640. [PubMed: 11432815]

23. Perry KJ, Higgins DE. A differential fluorescence-based genetic screen identifies Listeria monocytogenes determinants required for intracellular replication. J Bacteriol. 2013 in press. 10.1128/JB.00210-13

24. Glaser P, Frangeul L, Buchrieser C, Rusniok C, Amend A, Baquero F, Berche P, Bloecker H, Brandt P, Chakraborty T, Charbit A, Chetouani F, Couve E, de Daruvar A, Dehoux P, Domann E, Dominguez-Bernal G, Duchaud E, Durant L, Dussurget O, Entian KD, Fsihi H, Garcia-del Portillo F, Garrido P, Gautier L, Goebel W, Gomez-Lopez N, Hain T, Hauf J, Jackson D, Jones LM, Kaerst U, Kreft J, Kuhn M, Kunst F, Kurapkat G, Madueno E, Maitournam A, Vicente JM, Ng E, 
Nedjari H, Nordsiek G, Novella S, de Pablos B, Perez-Diaz JC, Purcell R, Remmel B, Rose M, Schlueter T, Simoes N, Tierrez A, Vazquez-Boland JA, Voss H, Wehland J, Cossart P. Comparative genomics of Listeria species. Science. 2001; 294:849-852. [PubMed: 11679669]

25. Joseph B, Przybilla K, Stuhler C, Schauer K, Slaghuis J, Fuchs TM, Goebel W. Identification of Listeria monocytogenes genes contributing to intracellular replication by expression profiling and mutant screening. J Bacteriol. 2006; 188:556-568. [PubMed: 16385046]

26. Gaillard JL, Berche P, Mounier J, Richard S, Sansonetti P. In vitro model of penetration and intracellular growth of Listeria monocytogenes in the human enterocyte-like cell line Caco-2. Infect Immun. 1987; 55:2822-2829. [PubMed: 3117693]

27. Braun L, Ohayon H, Cossart P. The InIB protein of Listeria monocytogenes is sufficient to promote entry into mammalian cells. Mol Microbiol. 1998; 27:1077-1087. [PubMed: 9535096]

28. Dramsi S, Biswas I, Maguin E, Braun L, Mastroeni P, Cossart P. Entry of Listeria monocytogenes into hepatocytes requires expression of inIB, a surface protein of the internalin multigene family. Mol Microbiol. 1995; 16:251-261. [PubMed: 7565087]

29. Gaillard JL, Berche P, Frehel C, Gouin E, Cossart P. Entry of L. monocytogenes into cells is mediated by internalin, a repeat protein reminiscent of surface antigens from gram-positive cocci. Cell. 1991; 65:1127-1141. [PubMed: 1905979]

30. Jonquieres R, Bierne H, Fiedler F, Gounon P, Cossart P. Interaction between the protein InlB of Listeria monocytogenes and lipoteichoic acid: a novel mechanism of protein association at the surface of gram-positive bacteria. Mol Microbiol. 1999; 34:902-914. [PubMed: 10594817]

31. Jonquieres R, Pizarro-Cerda J, Cossart P. Synergy between the N- and C-terminal domains of InlB for efficient invasion of non-phagocytic cells by Listeria monocytogenes. Mol Microbiol. 2001; 42:955-965. [PubMed: 11737639]

32. Marino M, Banerjee M, Jonquieres R, Cossart P, Ghosh P. GW domains of the Listeria monocytogenes invasion protein InlB are SH3-like and mediate binding to host ligands. EMBO J. 2002; 21:5623-5634. [PubMed: 12411480]

33. Pizarro-Cerda J, Kuhbacher A, Cossart P. Entry of Listeria monocytogenes in mammalian epithelial cells: an updated view. Cold Spring Harb Perspect Med. 2012; 2:a010009. [PubMed: 23125201]

34. Seveau S, Pizarro-Cerda J, Cossart P. Molecular mechanisms exploited by Listeria monocytogenes during host cell invasion. Microbes Infect. 2007; 9:1167-1175. [PubMed: 17761447]

35. Geoffroy C, Gaillard JL, Alouf JE, Berche P. Purification, characterization, and toxicity of the sulfhydryl-activated hemolysin listeriolysin O from Listeria monocytogenes. Infect Immun. 1987; 55:1641-1646. [PubMed: 3110067]

36. Geoffroy C, Gaillard JL, Alouf JE, Berche P. Production of thiol-dependent haemolysins by Listeria monocytogenes and related species. J Gen Microbiol. 1989; 135:481-487. [PubMed: 2516113]

37. Portnoy DA, Jacks PS, Hinrichs DJ. Role of hemolysin for the intracellular growth of Listeria monocytogenes. J Exp Med. 1988; 167:1459-1471. [PubMed: 2833557]

38. Cossart P, Vicente MF, Mengaud J, Baquero F, Perez-Diaz JC, Berche P. Listeriolysin O is essential for virulence of Listeria monocytogenes: direct evidence obtained by gene complementation. Infect Immun. 1989; 57:3629-3636. [PubMed: 2509366]

39. Gaillard JL, Berche P, Sansonetti P. Transposon mutagenesis as a tool to study the role of hemolysin in the virulence of Listeria monocytogenes. Infect Immun. 1986; 52:50-55. [PubMed: 3007363]

40. Kathariou S, Metz P, Hof H, Goebel W. Tn916-induced mutations in the hemolysin determinant affecting virulence of Listeria monocytogenes. J Bacteriol. 1987; 169:1291-1297. [PubMed: 3029033]

41. Mengaud J, Chenevert J, Geoffroy C, Gaillard JL, Cossart P. Identification of the structural gene encoding the $\mathrm{SH}$-activated hemolysin of Listeria monocytogenes: listeriolysin $\mathrm{O}$ is homologous to streptolysin O and pneumolysin. Infect Immun. 1987; 55:3225-3227. [PubMed: 2824384]

42. Kocks C, Gouin E, Tabouret M, Berche P, Ohayon H, Cossart P. L. monocytogenes-induced actin assembly requires the actA gene product, a surface protein. Cell. 1992; 68:521-531. [PubMed: 1739966] 
43. Welch MD, Rosenblatt J, Skoble J, Portnoy DA, Mitchison TJ. Interaction of human Arp2/3 complex and the Listeria monocytogenes ActA protein in actin filament nucleation. Science. 1998; 281:105-108. [PubMed: 9651243]

44. Mounier J, Ryter A, Coquis-Rondon M, Sansonetti PJ. Intracellular and cell-to-cell spread of Listeria monocytogenes involves interaction with F-actin in the enterocytelike cell line Caco-2. Infect Immun. 1990; 58:1048-1058. [PubMed: 2108086]

45. Tilney LG, Portnoy DA. Actin filaments and the growth, movement, and spread of the intracellular bacterial parasite, Listeria monocytogenes. J Cell Biol. 1989; 109:1597-1608. [PubMed: 2507553]

46. Gedde MM, Higgins DE, Tilney LG, Portnoy DA. Role of listeriolysin O in cell-to-cell spread of Listeria monocytogenes. Infect Immun. 2000; 68:999-1003. [PubMed: 10639481]

47. Sun AN, Camilli A, Portnoy DA. Isolation of Listeria monocytogenes small-plaque mutants defective for intracellular growth and cell-to-cell spread. Infect Immun. 1990; 58:3770-3778. [PubMed: 2172168]

48. Smith GA, Marquis H, Jones S, Johnston NC, Portnoy DA, Goldfine H. The two distinct phospholipases $\mathrm{C}$ of Listeria monocytogenes have overlapping roles in escape from a vacuole and cell-to-cell spread. Infect Immun. 1995; 63:4231-4237. [PubMed: 7591052]

49. Hamon MA, Batsche E, Regnault B, Tham TN, Seveau S, Muchardt C, Cossart P. Histone modifications induced by a family of bacterial toxins. Proc Natl Acad Sci USA. 2007; 104:1346713472. [PubMed: 17675409]

50. Hamon MA, Ribet D, Stavru F, Cossart P. Listeriolysin O: the Swiss army knife of Listeria. Trends Microbiol. 2012; 20:360-368. [PubMed: 22652164]

51. Chakraborty T, Leimeister-Wachter M, Domann E, Hartl M, Goebel W, Nichterlein T, Notermans $\mathrm{S}$. Coordinate regulation of virulence genes in Listeria monocytogenes requires the product of the prfA gene. J Bacteriol. 1992; 174:568-574. [PubMed: 1729245]

52. de las Heras A, Cain RJ, Bielecka MK, Vazquez-Boland JA. Regulation of Listeria virulence: PrfA master and commander. Curr Opin Microbiol. 2011; 14:118-127. [PubMed: 21388862]

53. Leimeister-Wachter M, Haffner C, Domann E, Goebel W, Chakraborty T. Identification of a gene that positively regulates expression of listeriolysin, the major virulence factor of listeria monocytogenes. Proc Natl Acad Sci USA. 1990; 87:8336-8340. [PubMed: 2122460]

54. Freitag NE, Youngman P, Portnoy DA. Transcriptional activation of the Listeria monocytogenes hemolysin gene in Bacillus subtilis. J Bacteriol. 1992; 174:1293-1298. [PubMed: 1735720]

55. Behari J, Youngman P. Regulation of hly expression in Listeria monocytogenes by carbon sources and $\mathrm{pH}$ occurs through separate mechanisms mediated by PrfA. Infect Immun. 1998; 66:36353642. [PubMed: 9673243]

56. Datta AR, Kothary MH. Effects of glucose, growth temperature, and $\mathrm{pH}$ on listeriolysin O production in Listeria monocytogenes. Appl Environ Microbiol. 1993; 59:3495-3497. [PubMed: 8250571]

57. Milenbachs AA, Brown DP, Moors M, Youngman P. Carbon-source regulation of virulence gene expression in Listeria monocytogenes. Mol Microbiol. 1997; 23:1075-1085. [PubMed: 9076743]

58. Johansson J, Mandin P, Renzoni A, Chiaruttini C, Springer M, Cossart P. An RNA thermosensor controls expression of virulence genes in Listeria monocytogenes. Cell. 2002; 110:551-561. [PubMed: 12230973]

59. Leimeister-Wachter M, Domann E, Chakraborty T. The expression of virulence genes in Listeria monocytogenes is thermoregulated. J Bacteriol. 1992; 174:947-952. [PubMed: 1732227]

60. Bubert A, Sokolovic Z, Chun SK, Papatheodorou L, Simm A, Goebel W. Differential expression of Listeria monocytogenes virulence genes in mammalian host cells. Mol Gen Genet. 1999; 261:323-336. [PubMed: 10102368]

61. Shen A, Higgins DE. The 5' untranslated region-mediated enhancement of intracellular listeriolysin $\mathrm{O}$ production is required for Listeria monocytogenes pathogenicity. Mol Microbiol. 2005; 57:1460-1473. [PubMed: 16102013]

62. Schnupf P, Portnoy DA, Decatur AL. Phosphorylation, ubiquitination and degradation of listeriolysin O in mammalian cells: role of the PEST-like sequence. Cell Microbiol. 2006; 8:353364. [PubMed: 16441444] 
63. Mengaud J, Vicente MF, Chenevert J, Pereira JM, Geoffroy C, Gicquel-Sanzey B, Baquero F, Perez-Diaz JC, Cossart P. Expression in Escherichia coli and sequence analysis of the listeriolysin O determinant of Listeria monocytogenes. Infect Immun. 1988; 56:766-772. [PubMed: 3126142]

64. Arnett E, Lehrer RI, Pratikhya P, Lu W, Seveau S. Defensins enable macrophages to inhibit the intracellular proliferation of Listeria monocytogenes. Cell Microbiol. 2011; 13:635-651. [PubMed: 21143570]

65. Lehrer RI, Jung G, Ruchala P, Wang W, Micewicz ED, Waring AJ, Gillespie EJ, Bradley KA, Ratner AJ, Rest RF, Lu W. Human alpha-defensins inhibit hemolysis mediated by cholesteroldependent cytolysins. Infect Immun. 2009; 77:4028-4040. [PubMed: 19581399]

66. Arnett E, Seveau S. The multifaceted activities of mammalian defensins. Curr Pharm Des. 2011; 17:4254-4269. [PubMed: 22204426]

67. Koster S, Hudel M, Chakraborty T, Yildiz O. Crystallization and X-ray crystallographic analysis of the cholesterol-dependent cytolysin listeriolysin O from Listeria monocytogenes. Acta Crystallogr, Sect F: Struct Biol Cryst Commun. 2013; 69:1212-1215.

68. Dunstone MA, Tweten RK. Packing a punch: the mechanism of pore formation by cholesterol dependent cytolysins and membrane attack complex/perforin-like proteins. Curr Opin Struct Biol. 2012; 22:342-349. [PubMed: 22658510]

69. Rossjohn J, Feil SC, McKinstry WJ, Tweten RK, Parker MW. Structure of a cholesterol-binding, thiol-activated cytolysin and a model of its membrane form. Cell. 1997; 89:685-692. [PubMed: 9182756]

70. Heuck AP, Moe PC, Johnson BB. The cholesterol-dependent cytolysin family of gram-positive bacterial toxins. Subcell Biochem. 2010; 51:551-577. [PubMed: 20213558]

71. Hotze EM, Tweten RK. Membrane assembly of the cholesterol-dependent cytolysin pore complex. Biochim Biophys Acta. 2012; 1818:1028-1038. [PubMed: 21835159]

72. Ramachandran R, Heuck AP, Tweten RK, Johnson AE. Structural insights into the membraneanchoring mechanism of a cholesterol-dependent cytolysin. Nat Struct Biol. 2002; 9:823-827. [PubMed: 12368903]

73. Solovyova AS, Nollmann M, Mitchell TJ, Byron O. The solution structure and oligomerization behavior of two bacterial toxins: pneumolysin and perfringolysin O. Biophys J. 2004; 87:540-552. [PubMed: 15240487]

74. Palmer M, Harris R, Freytag C, Kehoe M, Tranum-Jensen J, Bhakdi S. Assembly mechanism of the oligomeric streptolysin $\mathrm{O}$ pore: the early membrane lesion is lined by a free edge of the lipid membrane and is extended gradually during oligomerization. EMBO J. 1998; 17:1598-1605. [PubMed: 9501081]

75. Repp H, Pamukci Z, Koschinski A, Domann E, Darji A, Birringer J, Brockmeier D, Chakraborty T, Dreyer F. Listeriolysin of Listeria monocytogenes forms Ca2+-permeable pores leading to intracellular Ca2+ oscillations. Cell Microbiol. 2002; 4:483-491. [PubMed: 12174083]

76. Shaughnessy LM, Hoppe AD, Christensen KA, Swanson JA. Membrane perforations inhibit lysosome fusion by altering $\mathrm{pH}$ and calcium in Listeria monocytogenes vacuoles. Cell Microbiol. 2006; 8:781-792. [PubMed: 16611227]

77. Ramachandran R, Tweten RK, Johnson AE. Membrane-dependent conformational changes initiate cholesterol-dependent cytolysin oligomerization and intersubunit beta-strand alignment. Nat Struct Mol Biol. 2004; 11:697-705. [PubMed: 15235590]

78. Soltani CE, Hotze EM, Johnson AE, Tweten RK. Specific protein-membrane contacts are required for prepore and pore assembly by a cholesterol-dependent cytolysin. J Biol Chem. 2007; 282:15709-15716. [PubMed: 17412689]

79. Farrand AJ, LaChapelle S, Hotze EM, Johnson AE, Tweten RK. Only two amino acids are essential for cytolytic toxin recognition of cholesterol at the membrane surface. Proc Natl Acad Sci USA. 2010; 107:4341-4346. [PubMed: 20145114]

80. Bavdek A, Gekara NO, Priselac D, Gutierrez Aguirre I, Darji A, Chakraborty T, Macek P, Lakey JH, Weiss S, Anderluh G. Sterol and pH interdependence in the binding, oligomerization, and pore formation of Listeriolysin O. Biochemistry. 2007; 46:4425-4437. [PubMed: 17358050]

81. Coconnier MH, Lorrot M, Barbat A, Laboisse C, Servin AL. Listeriolysin O-induced stimulation of mucin exocytosis in polarized intestinal mucin-secreting cells: evidence for toxin recognition of 
membrane-associated lipids and subsequent toxin internalization through caveolae. Cell Microbiol. 2000; 2:487-504. [PubMed: 11207603]

82. Gelber SE, Aguilar JL, Lewis KL, Ratner AJ. Functional and phylogenetic characterization of Vaginolysin, the human-specific cytolysin from Gardnerella vaginalis. J Bacteriol. 2008; 190:3896-3903. [PubMed: 18390664]

83. Giddings KS, Zhao J, Sims PJ, Tweten RK. Human CD59 is a receptor for the cholesteroldependent cytolysin intermedilysin. Nat Struct Mol Biol. 2004; 11:1173-1178. [PubMed: 15543155]

84. Jacobs T, Darji A, Frahm N, Rohde M, Wehland J, Chakraborty T, Weiss S. Listeriolysin O: cholesterol inhibits cytolysis but not binding to cellular membranes. Mol Microbiol. 1998; 28:1081-1089. [PubMed: 9680200]

85. Dowd KJ, Tweten RK. The cholesterol-dependent cytolysin signature motif: a critical element in the allosteric pathway that couples membrane binding to pore assembly. PLoS Pathog. 2012; 8:e1002787. [PubMed: 22792065]

86. Shatursky O, Heuck AP, Shepard LA, Rossjohn J, Parker MW, Johnson AE, Tweten RK. The mechanism of membrane insertion for a cholesterol-dependent cytolysin: a novel paradigm for pore-forming toxins. Cell. 1999; 99:293-299. [PubMed: 10555145]

87. Shepard LA, Heuck AP, Hamman BD, Rossjohn J, Parker MW, Ryan KR, Johnson AE, Tweten RK. Identification of a membrane-spanning domain of the thiol-activated pore-forming toxin Clostridium perfringens perfringolysin O: an alpha-helical to beta-sheet transition identified by fluorescence spectroscopy. Biochemistry. 1998; 37:14563-14574. [PubMed: 9772185]

88. Hotze EM, Wilson-Kubalek EM, Rossjohn J, Parker MW, Johnson AE, Tweten RK. Arresting pore formation of a cholesterol-dependent cytolysin by disulfide trapping synchronizes the insertion of the transmembrane beta-sheet from a prepore intermediate. J Biol Chem. 2001; 276:8261-8268. [PubMed: 11102453]

89. Vadia S, Arnett E, Haghighat AC, Wilson-Kubalek EM, Tweten RK, Seveau S. The pore-forming toxin listeriolysin $\mathrm{O}$ mediates a novel entry pathway of L. monocytogenes into human hepatocytes. PLoS Pathog. 2011; 7:e1002356. [PubMed: 22072970]

90. Schnupf P, Portnoy DA. Listeriolysin O: a phagosome-specific lysin. Microbes Infect. 2007; 9:1176-1187. [PubMed: 17720603]

91. Bavdek A, Kostanjsek R, Antonini V, Lakey JH, Dalla Serra M, Gilbert RJ, Anderluh G. pH dependence of listeriolysin O aggregation and pore-forming ability. FEBS J. 2012; 279:126-141. [PubMed: 22023160]

92. Schuerch DW, Wilson-Kubalek EM, Tweten RK. Molecular basis of listeriolysin O pH dependence. Proc Natl Acad Sci USA. 2005; 102:12537-12542. [PubMed: 16105950]

93. Ribet D, Hamon M, Gouin E, Nahori MA, Impens F, Neyret-Kahn H, Gevaert K, Vandekerckhove J, Dejean A, Cossart P. Listeria monocytogenes impairs SUMOylation for efficient infection. Nature. 2010; 464:1192-1195. [PubMed: 20414307]

94. Stavru F, Bouillaud F, Sartori A, Ricquier D, Cossart P. Listeria monocytogenes transiently alters mitochondrial dynamics during infection. Proc Natl Acad Sci USA. 2011; 108:3612-3617. [PubMed: 21321208]

95. Glomski IJ, Gedde MM, Tsang AW, Swanson JA, Portnoy DA. The Listeria monocytogenes hemolysin has an acidic $\mathrm{pH}$ optimum to compartmentalize activity and prevent damage to infected host cells. J Cell Biol. 2002; 156:1029-1038. [PubMed: 11901168]

96. Michel E, Reich KA, Favier R, Berche P, Cossart P. Attenuated mutants of the intracellular bacterium Listeria monocytogenes obtained by single amino acid substitutions in listeriolysin $\mathrm{O}$. Mol Microbiol. 1990; 4:2167-2178. [PubMed: 1965218]

97. Singh R, Jamieson A, Cresswell P. GILT is a critical host factor for Listeria monocytogenes infection. Nature. 2008; 455:1244-1247. [PubMed: 18815593]

98. Burrack LS, Harper JW, Higgins DE. Perturbation of vacuolar maturation promotes listeriolysin Oindependent vacuolar escape during Listeria monocytogenes infection of human cells. Cell Microbiol. 2009; 11:1382-1398. [PubMed: 19500109] 
99. Grundling A, Gonzalez MD, Higgins DE. Requirement of the Listeria monocytogenes broad-range phospholipase PC-PLC during infection of human epithelial cells. J Bacteriol. 2003; 185:62956307. [PubMed: 14563864]

100. Marquis H, Doshi V, Portnoy DA. The broad-range phospholipase C and a metalloprotease mediate listeriolysin O-independent escape of Listeria monocytogenes from a primary vacuole in human epithelial cells. Infect Immun. 1995; 63:4531-4534. [PubMed: 7591098]

101. Camilli A, Tilney LG, Portnoy DA. Dual roles of plcA in Listeria monocytogenes pathogenesis. Mol Microbiol. 1993; 8:143-157. [PubMed: 8388529]

102. Wadsworth SJ, Goldfine H. Mobilization of protein kinase $\mathrm{C}$ in macrophages induced by Listeria monocytogenes affects its internalization and escape from the phagosome. Infect Immun. 2002; 70:4650-4660. [PubMed: 12117979]

103. Beauregard KE, Lee KD, Collier RJ, Swanson JA. pH-dependent perforation of macrophage phagosomes by listeriolysin O from Listeria monocytogenes. J Exp Med. 1997; 186:1159-1163. [PubMed: 9314564]

104. Henry R, Shaughnessy L, Loessner MJ, Alberti-Segui C, Higgins DE, Swanson JA. Cytolysindependent delay of vacuole maturation in macrophages infected with Listeria monocytogenes. Cell Microbiol. 2006; 8:107-119. [PubMed: 16367870]

105. Radtke AL, Anderson KL, Davis MJ, DiMagno MJ, Swanson JA, O'Riordan MX. Listeria monocytogenes exploits cystic fibrosis transmembrane conductance regulator (CFTR) to escape the phagosome. Proc Natl Acad Sci USA. 2011; 108:1633-1638. [PubMed: 21220348]

106. Lam GY, Fattouh R, Muise AM, Grinstein S, Higgins DE, Brumell JH. Listeriolysin O suppresses phospholipase C-mediated activation of the microbicidal NADPH oxidase to promote Listeria monocytogenes infection. Cell Host Microbe. 2011; 10:627-634. [PubMed: 22177565]

107. Madden JC, Ruiz N, Caparon M. Cytolysin-mediated translocation (CMT): a functional equivalent of type III secretion in gram-positive bacteria. Cell. 2001; 104:143-152. [PubMed: 11163247]

108. Shaughnessy LM, Swanson JA. The role of the activated macrophage in clearing Listeria monocytogenes infection. Front Biosci. 2007; 12:2683-2692. [PubMed: 17127272]

109. Arnett E, Vadia S, Nackerman CC, Oghumu S, Satoskar AR, McLeish KR, Uriarte SM, Seveau $\mathrm{S}$. The pore-forming toxin listeriolysin $\mathrm{O}$ is degraded by neutrophil metalloproteiase- 8 and is fails to mediate Listeria monocytogenes intracellular survival in neutrophils. J Immunol. 2014 in press. 10.4049/jimmunol.1301302

110. Myers JT, Tsang AW, Swanson JA. Localized reactive oxygen and nitrogen intermediates inhibit escape of Listeria monocytogenes from vacuoles in activated macrophages. J Immunol. 2003; 171:5447-5453. [PubMed: 14607950]

111. del Cerro-Vadillo E, Madrazo-Toca F, Carrasco-Marin E, Fernandez-Prieto L, Beck C, LeyvaCobian F, Saftig P, Alvarez-Dominguez C. Cutting edge: a novel nonoxidative phagosomal mechanism exerted by cathepsin-D controls Listeria monocytogenes intracellular growth. J Immunol. 2006; 176:1321-1325. [PubMed: 16424157]

112. Davis MJ, Gregorka B, Gestwicki JE, Swanson JA. Inducible renitence limits Listeria monocytogenes escape from vacuoles in macrophages. J Immunol. 2012; 189:4488-4495. [PubMed: 23002437]

113. Birmingham CL, Canadien V, Gouin E, Troy EB, Yoshimori T, Cossart P, Higgins DE, Brumell JH. Listeria monocytogenes evades killing by autophagy during colonization of host cells. Autophagy. 2007; 3:442-451. [PubMed: 17568179]

114. Py BF, Lipinski MM, Yuan J. Autophagy limits Listeria monocytogenes intracellular growth in the early phase of primary infection. Autophagy. 2007; 3:117-125. [PubMed: 17204850]

115. Meyer-Morse N, Robbins JR, Rae CS, Mochegova SN, Swanson MS, Zhao Z, Virgin HW, Portnoy D. Listeriolysin $\mathrm{O}$ is necessary and sufficient to induce autophagy during Listeria monocytogenes infection. PLoS ONE. 2010; 5:e8610. [PubMed: 20062534]

116. Dortet L, Mostowy S, Samba-Louaka A, Gouin E, Nahori MA, Wiemer EA, Dussurget O, Cossart P. Recruitment of the major vault protein by InlK: a Listeria monocytogenes strategy to avoid autophagy. PLoS Pathog. 2011; 7:e1002168. [PubMed: 21829365] 
117. Alberti-Segui C, Goeden KR, Higgins DE. Differential function of Listeria monocytogenes listeriolysin $\mathrm{O}$ and phospholipases $\mathrm{C}$ in vacuolar dissolution following cell-to-cell spread. Cell Microbiol. 2007; 9:179-195. [PubMed: 17222191]

118. Dancz CE, Haraga A, Portnoy DA, Higgins DE. Inducible control of virulence gene expression in Listeria monocytogenes: temporal requirement of listeriolysin $\mathrm{O}$ during intracellular infection. $\mathrm{J}$ Bacteriol. 2002; 184:5935-5945. [PubMed: 12374827]

119. Villanueva MS, Sijts AJ, Pamer EG. Listeriolysin is processed efficiently into an MHC class Iassociated epitope in Listeria monocytogenes-infected cells. J Immunol. 1995; 155:5227-5233. [PubMed: 7594534]

120. Decatur AL, Portnoy DA. A PEST-like sequence in listeriolysin O essential for Listeria monocytogenes pathogenicity. Science. 2000; 290:992-995. [PubMed: 11062133]

121. Glomski IJ, Decatur AL, Portnoy DA. Listeria monocytogenes mutants that fail to compartmentalize listerolysin $\mathrm{O}$ activity are cytotoxic, avirulent, and unable to evade host extracellular defenses. Infect Immun. 2003; 71:6754-6765. [PubMed: 14638761]

122. Frehel C, Lety MA, Autret N, Beretti JL, Berche P, Charbit A. Capacity of ivanolysin O to replace listeriolysin $\mathrm{O}$ in phagosomal escape and in vivo survival of Listeria monocytogenes. Microbiology. 2003; 149:611-620. [PubMed: 12634330]

123. Jones S, Portnoy DA. Characterization of Listeria monocytogenes pathogenesis in a strain expressing perfringolysin O in place of listeriolysin O. Infect Immun. 1994; 62:5608-5613. [PubMed: 7960143]

124. Wei Z, Schnupf P, Poussin MA, Zenewicz LA, Shen H, Goldfine H. Characterization of Listeria monocytogenes expressing anthrolysin $\mathrm{O}$ and phosphatidylinositol-specific phospholipase $\mathrm{C}$ from Bacillus anthracis. Infect Immun. 2005; 73:6639-6646. [PubMed: 16177340]

125. Carrero JA, Calderon B, Unanue ER. Listeriolysin O from Listeria monocytogenes is a lymphocyte apoptogenic molecule. J Immunol. 2004; 172:4866-4874. [PubMed: 15067065]

126. Lety MA, Frehel C, Dubail I, Beretti JL, Kayal S, Berche P, Charbit A. Identification of a PESTlike motif in listeriolysin $\mathrm{O}$ required for phagosomal escape and for virulence in Listeria monocytogenes. Mol Microbiol. 2001; 39:1124-1139. [PubMed: 11251831]

127. Schnupf P, Zhou J, Varshavsky A, Portnoy DA. Listeriolysin O secreted by Listeria monocytogenes into the host cell cytosol is degraded by the $\mathrm{N}$-end rule pathway. Infect Immun. 2007; 75:5135-5147. [PubMed: 17682039]

128. Viala JP, Mochegova SN, Meyer-Morse N, Portnoy DA. A bacterial pore-forming toxin forms aggregates in cells that resemble those associated with neurodegenerative diseases. Cell Microbiol. 2008; 10:985-993. [PubMed: 18067608]

129. Tsuchiya K, Kawamura I, Takahashi A, Nomura T, Kohda C, Mitsuyama M. Listeriolysin Oinduced membrane permeation mediates persistent interleukin- 6 production in Caco- 2 cells during Listeria monocytogenes infection in vitro. Infect Immun. 2005; 73:3869-3877. [PubMed: 15972472]

130. Cassidy SK, Hagar JA, Kanneganti TD, Franchi L, Nunez G, O’Riordan MX. Membrane damage during Listeria monocytogenes infection triggers a caspase-7 dependent cytoprotective response. PLoS Pathog. 2012; 8:e1002628. [PubMed: 22807671]

131. Vadia S, Seveau S. Fluxes of $\mathrm{Ca} 2+$ and $\mathrm{K}+$ are required for the LLO-dependent internalization pathway of Listeria monocytogenes. Infect Immun. 2014 in press.

132. Abreu-Blanco MT, Verboon JM, Parkhurst SM. Single cell wound repair: dealing with life's little traumas. Bioarchitecture. 2011; 1:114-121. [PubMed: 21922041]

133. McNeil PL. Repairing a torn cell surface: make way, lysosomes to the rescue. J Cell Sci. 2002; 115:873-879. [PubMed: 11870206]

134. Steinhardt RA. The mechanisms of cell membrane repair: a tutorial guide to key experiments. Ann N Y Acad Sci. 2005; 1066:152-165. [PubMed: 16533925]

135. Draeger A, Monastyrskaya K, Babiychuk EB. Plasma membrane repair and cellular damage control: the annexin survival kit. Biochem Pharmacol. 2011; 81:703-712. [PubMed: 21219882]

136. Idone V, Tam C, Goss JW, Toomre D, Pypaert M, Andrews NW. Repair of injured plasma membrane by rapid Ca2+-dependent endocytosis. J Cell Biol. 2008; 180:905-914. [PubMed: 18316410] 
137. Rodriguez A, Webster P, Ortego J, Andrews NW. Lysosomes behave as Ca2+-regulated exocytic vesicles in fibroblasts and epithelial cells. J Cell Biol. 1997; 137:93-104. [PubMed: 9105039]

138. Steinhardt RA, Bi G, Alderton JM. Cell membrane resealing by a vesicular mechanism similar to neurotransmitter release. Science. 1994; 263:390-393. [PubMed: 7904084]

139. Tam C, Idone V, Devlin C, Fernandes MC, Flannery A, He X, Schuchman E, Tabas I, Andrews NW. Exocytosis of acid sphingomyelinase by wounded cells promotes endocytosis and plasma membrane repair. J Cell Biol. 2010; 189:1027-1038. [PubMed: 20530211]

140. Zha X, Pierini LM, Leopold PL, Skiba PJ, Tabas I, Maxfield FR. Sphingomyelinase treatment induces ATP-independent endocytosis. J Cell Biol. 1998; 140:39-47. [PubMed: 9425152]

141. Corrotte M, Fernandes MC, Tam C, Andrews NW. Toxin pores endocytosed during plasma membrane repair traffic into the lumen of MVBs for degradation. Traffic. 2012; 13:483-494. [PubMed: 22212686]

142. Potez S, Luginbuhl M, Monastyrskaya K, Hostettler A, Draeger A, Babiychuk EB. Tailored protection against plasmalemmal injury by annexins with different $\mathrm{Ca} 2+$ sensitivities. J Biol Chem. 2011; 286:17982-17991. [PubMed: 21454475]

143. Dong Z, Saikumar P, Weinberg JM, Venkatachalam MA. Calcium in cell injury and death. Annu Rev Pathol. 2006; 1:405-434. [PubMed: 18039121]

144. Gekara NO, Weiss S. Lipid rafts clustering and signalling by listeriolysin O. Biochem Soc Trans. 2004; 32:712-714. [PubMed: 15493995]

145. Dramsi S, Cossart P. Listeriolysin O-mediated calcium influx potentiates entry of Listeria monocytogenes into the human Hep-2 epithelial cell line. Infect Immun. 2003; 71:3614-3618. [PubMed: 12761148]

146. Gekara NO, Westphal K, Ma B, Rohde M, Groebe L, Weiss S. The multiple mechanisms of Ca2+ signalling by listeriolysin $\mathrm{O}$, the cholesterol-dependent cytolysin of Listeria monocytogenes. Cell Microbiol. 2007; 9:2008-2021. [PubMed: 17419718]

147. Rose F, Zeller SA, Chakraborty T, Domann E, Machleidt T, Kronke M, Seeger W, Grimminger F, Sibelius U. Human endothelial cell activation and mediator release in response to Listeria monocytogenes virulence factors. Infect Immun. 2001; 69:897-905. [PubMed: 11159983]

148. Wadsworth SJ, Goldfine H. Listeria monocytogenes phospholipase C-dependent calcium signaling modulates bacterial entry into J774 macrophage-like cells. Infect Immun. 1999; 67:1770-1778. [PubMed: 10085017]

149. Gonzalez MR, Bischofberger M, Freche B, Ho S, Parton RG, van der Goot FG. Poreforming toxins induce multiple cellular responses promoting survival. Cell Microbiol. 2011; 13:10261043. [PubMed: 21518219]

150. Arthur JS, Ley SC. Mitogen-activated protein kinases in innate immunity. Nat Rev Immunol. 2013; 13:679-692. [PubMed: 23954936]

151. Tang P, Sutherland CL, Gold MR, Finlay BB. Listeria monocytogenes invasion of epithelial cells requires the MEK-1/ERK-2 mitogen-activated protein kinase pathway. Infect Immun. 1998; 66:1106-1112. [PubMed: 9488402]

152. Weiglein I, Goebel W, Troppmair J, Rapp UR, Demuth A, Kuhn M. Listeria monocytogenes infection of HeLa cells results in listeriolysin O-mediated transient activation of the Raf-MEKMAP kinase pathway. FEMS Microbiol Lett. 1997; 148:189-195. [PubMed: 9084147]

153. Flotho A, Melchior F. Sumoylation: a regulatory protein modification in health and disease. Annu Rev Biochem. 2013; 82:357-385. [PubMed: 23746258]

154. Ribet D, Cossart P. SUMOylation and bacterial pathogens. Virulence. 2010; 1:532-534. [PubMed: 21178495]

155. Seveau S, Bierne H, Giroux S, Prevost MC, Cossart P. Role of lipid rafts in E-cadherin- and HGF-R/Met-mediated entry of Listeria monocytogenes into host cells. J Cell Biol. 2004; 166:743-753. [PubMed: 15337781]

156. Seveau S, Tham TN, Payrastre B, Hoppe AD, Swanson JA, Cossart P. A FRET analysis to unravel the role of cholesterol in Rac1 and PI 3-kinase activation in the InlB/Met signalling pathway. Cell Microbiol. 2007; 9:790-803. [PubMed: 17140407] 
157. Fernandes MC, Cortez M, Flannery AR, Tam C, Mortara RA, Andrews NW. Trypanosoma cruzi subverts the sphingomyelinase-mediated plasma membrane repair pathway for cell invasion. $\mathrm{J}$ Exp Med. 2011; 208:909-921. [PubMed: 21536739]

158. Logsdon LK, Hakansson AP, Cortes G, Wessels MR. Streptolysin o inhibits clathrin-dependent internalization of group a streptococcus. MBio. 2011; 2:e00332-e00310. [PubMed: 21325037]

159. Sukeno A, Nagamune H, Whiley RA, Jafar SI, Aduse-Opoku J, Ohkura K, Maeda T, Hirota K, Miyake Y, Kourai H. Intermedilysin is essential for the invasion of hepatoma HepG2 cells by Streptococcus intermedius. Microbiol Immunol. 2005; 49:681-694. [PubMed: 16034212]

160. Sovolyova N, Healy S, Samali A, Logue SE. Stressed to death-mechanisms of ER stressinduced cell death. Biol Chem. 2014; 395:1-13. [PubMed: 24002662]

161. Carrara M, Prischi F, Ali MM. UPR signal activation by luminal sensor domains. Int J Mol Sci. 2013; 14:6454-6466. [PubMed: 23519110]

162. Pillich H, Loose M, Zimmer KP, Chakraborty T. Activation of the unfolded protein response by Listeria monocytogenes. Cell Microbiol. 2012; 14:949-964. [PubMed: 22321539]

163. Gekara NO, Groebe L, Viegas N, Weiss S. Listeria monocytogenes desensitizes immune cells to subsequent $\mathrm{Ca} 2+$ signaling via listeriolysin $\mathrm{O}$-induced depletion of intracellular $\mathrm{Ca} 2+$ stores. Infect Immun. 2008; 76:857-862. [PubMed: 18056478]

164. Schroder M, Kaufman RJ. The mammalian unfolded protein response. Annu Rev Biochem. 2005; 74:739-789. [PubMed: 15952902]

165. Bischof LJ, Kao CY, Los FC, Gonzalez MR, Shen Z, Briggs SP, van der Goot FG, Aroian RV. Activation of the unfolded protein response is required for defenses against bacterial poreforming toxin in vivo. PLoS Pathog. 2008; 4:e1000176. [PubMed: 18846208]

166. de Brito OM, Scorrano L. An intimate liaison: spatial organization of the endoplasmic reticulummitochondria relationship. EMBO J. 2010; 29:2715-2723. [PubMed: 20717141]

167. Stavru F, Palmer AE, Wang C, Youle RJ, Cossart P. Atypical mitochondrial fission upon bacterial infection. Proc Natl Acad Sci USA. 2013; 110:16003-16008. [PubMed: 24043775]

168. Bannister AJ, Kouzarides T. Regulation of chromatin by histone modifications. Cell Res. 2011; 21:381-395. [PubMed: 21321607]

169. Hamon MA, Cossart P. $\mathrm{K}+$ efflux is required for histone $\mathrm{H} 3$ dephosphorylation by Listeria monocytogenes listeriolysin $\mathrm{O}$ and other pore-forming toxins. Infect Immun. 2011; 79:2839_ 2846. [PubMed: 21482680]

170. Eitel J, Suttorp N, Opitz B. Innate immune recognition and inflammasome activation in listeria monocytogenes infection. Front Microbiol. 2010; 1:149. [PubMed: 21607087]

171. O’Riordan M, Yi CH, Gonzales R, Lee KD, Portnoy DA. Innate recognition of bacteria by a macrophage cytosolic surveillance pathway. Proc Natl Acad Sci USA. 2002; 99:13861-13866. [PubMed: 12359878]

172. Opitz B, Puschel A, Beermann W, Hocke AC, Forster S, Schmeck B, van Laak V, Chakraborty T, Suttorp N, Hippenstiel S. Listeria monocytogenes activated p38 MAPK and induced IL-8 secretion in a nucleotide-binding oligomerization domain 1-dependent manner in endothelial cells. J Immunol. 2006; 176:484-490. [PubMed: 16365441]

173. Gurcel L, Abrami L, Girardin S, Tschopp J, van der Goot FG. Caspase-1 activation of lipid metabolic pathways in response to bacterial pore-forming toxins promotes cell survival. Cell. 2006; 126:1135-1145. [PubMed: 16990137]

174. Meixenberger K, Pache F, Eitel J, Schmeck B, Hippenstiel S, Slevogt H, N'Guessan P, Witzenrath M, Netea MG, Chakraborty T, Suttorp N, Opitz B. Listeria monocytogenes-infected human peripheral blood mononuclear cells produce IL-1beta, depending on listeriolysin $\mathrm{O}$ and NLRP3. J Immunol. 2010; 184:922-930. [PubMed: 20008285]

175. Im SS, Osborne TF. Protection from bacterial-toxin-induced apoptosis in macrophages requires the lipogenic transcription factor sterol regulatory element binding protein 1a. Mol Cell Biol. 2012; 32:2196-2202. [PubMed: 22493063]

176. Kayal S, Lilienbaum A, Poyart C, Memet S, Israel A, Berche P. Listeriolysin O-dependent activation of endothelial cells during infection with Listeria monocytogenes: activation of NFkappa B and upregulation of adhesion molecules and chemokines. Mol Microbiol. 1999; 31:1709-1722. [PubMed: 10209744] 
177. Park JM, Ng VH, Maeda S, Rest RF, Karin M. Anthrolysin O and other gram-positive cytolysins are toll-like receptor 4 agonists. J Exp Med. 2004; 200:1647-1655. [PubMed: 15611291]

178. Sun R, Liu Y. Listeriolysin $O$ as a strong immunogenic molecule for the development of new anti-tumor vaccines. Hum Vaccin Immunother. 2013; 9:1058-1068. [PubMed: 23399758]

179. Wallecha A, Wood L, Pan ZK, Maciag PC, Shahabi V, Paterson Y. Listeria monocytogenesderived listeriolysin $\mathrm{O}$ has pathogen-associated molecular pattern-like properties independent of its hemolytic ability. Clin Vaccine Immunol. 2013; 20:77-84. [PubMed: 23136118]

180. Carrero JA, Unanue ER. Mechanisms and immunological effects of apoptosis caused by Listeria monocytogenes. Adv Immunol. 2012; 113:157-174. [PubMed: 22244583]

181. Rogers HW, Callery MP, Deck B, Unanue ER. Listeria monocytogenes induces apoptosis of infected hepatocytes. J Immunol. 1996; 156:679-684. [PubMed: 8543820]

182. Carrero JA, Calderon B, Vivanco-Cid H, Unanue ER. Recombinant Listeria monocytogenes expressing a cell wall-associated listeriolysin $\mathrm{O}$ is weakly virulent but immunogenic. Infect Immun. 2009; 77:4371-4382. [PubMed: 19667043]

183. Edelson BT, Cossart P, Unanue ER. Cutting edge: paradigm revisited: antibody provides resistance to Listeria infection. J Immunol. 1999; 163:4087-4090. [PubMed: 10510340]

184. Edelson BT, Unanue ER. Intracellular antibody neutralizes Listeria growth. Immunity. 2001; 14:503-512. [PubMed: 11371353]

185. Carrero JA, Vivanco-Cid H, Unanue ER. Granzymes drive a rapid listeriolysin O-induced T cell apoptosis. J Immunol. 2008; 181:1365-1374. [PubMed: 18606691]

186. Carrero JA, Calderon B, Unanue ER. Type I interferon sensitizes lymphocytes to apoptosis and reduces resistance to Listeria infection. J Exp Med. 2004; 200:535-540. [PubMed: 15302900]

187. Carrero JA, Unanue ER. Impact of lymphocyte apoptosis on the innate immune stages of infection. Immunol Res. 2007; 38:333-341. [PubMed: 17917040]

188. Cossart P. Illuminating the landscape of host-pathogen interactions with the bacterium Listeria monocytogenes. Proc Natl Acad Sci USA. 2011; 108:19484-19491. [PubMed: 22114192]

189. Rajabian T, Gavicherla B, Heisig M, Muller-Altrock S, Goebel W, Gray-Owen SD, Ireton K. The bacterial virulence factor InlC perturbs apical cell junctions and promotes cell-to-cell spread of Listeria. Nat Cell Biol. 2009; 11:1212-1218. [PubMed: 19767742] 


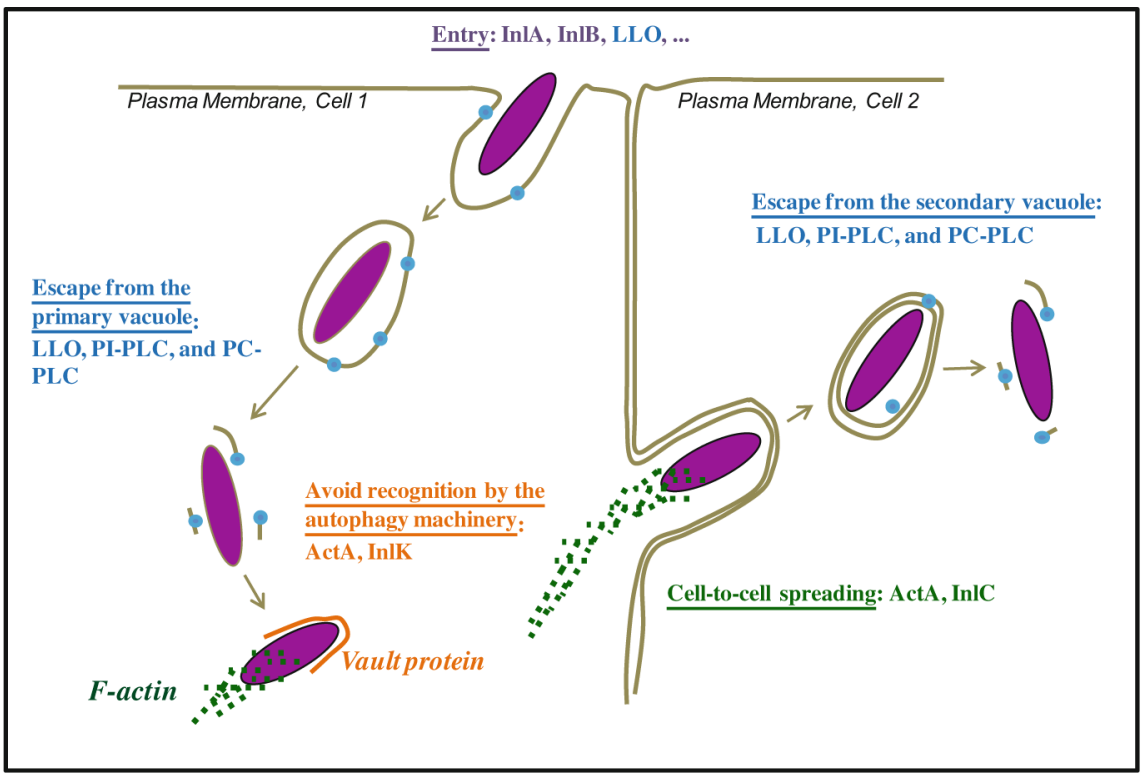

Fig. 9.1.

Depiction of the canonical intracellular lifecycle of L. monocytogenes. L. monocytogenes expresses virulence factors that orchestrate the various stages of its intracellular lifecycle [33, 34, 90, 188]. The surface proteins InlA and InlB facilitate L. monocytogenes internalization into normally nonphagocytic cells. Additional virulence factors, such as the secreted CDC toxin LLO, also mediate L. monocytogenes entry into host cells (cell 1) [33, 89]. Secreted in the primary vacuole, LLO, PI-PLC, and PC-PLC target and disrupt the vacuolar membrane to release the bacterium into the cytosol. In the cytosol, $L$. monocytogenes replicates, while avoiding autophagy recognition by recruiting the host proteins F-actin and the major vault protein, through interaction with the bacterial surface proteins ActA and InlK, respectively [116]. ActA recruits the host F-actin polymerization machinery at one pole of the bacterium. F-actin-mediated propulsion of the bacterium leads to the formation of an intercellular protrusion; this process is facilitated by the bacterial protein InlC that decreases the plasma membrane surface tension [189]. The resulting intercellular protrusion is ingested by the adjacent cell (cell 2). LLO and the phospholipases (PI-PLC and PC-PLC) disrupt the newly formed secondary vacuole to release the bacterium into the cytosol, where it repeats its intracellular lifecycle (Host proteins are italicized) 


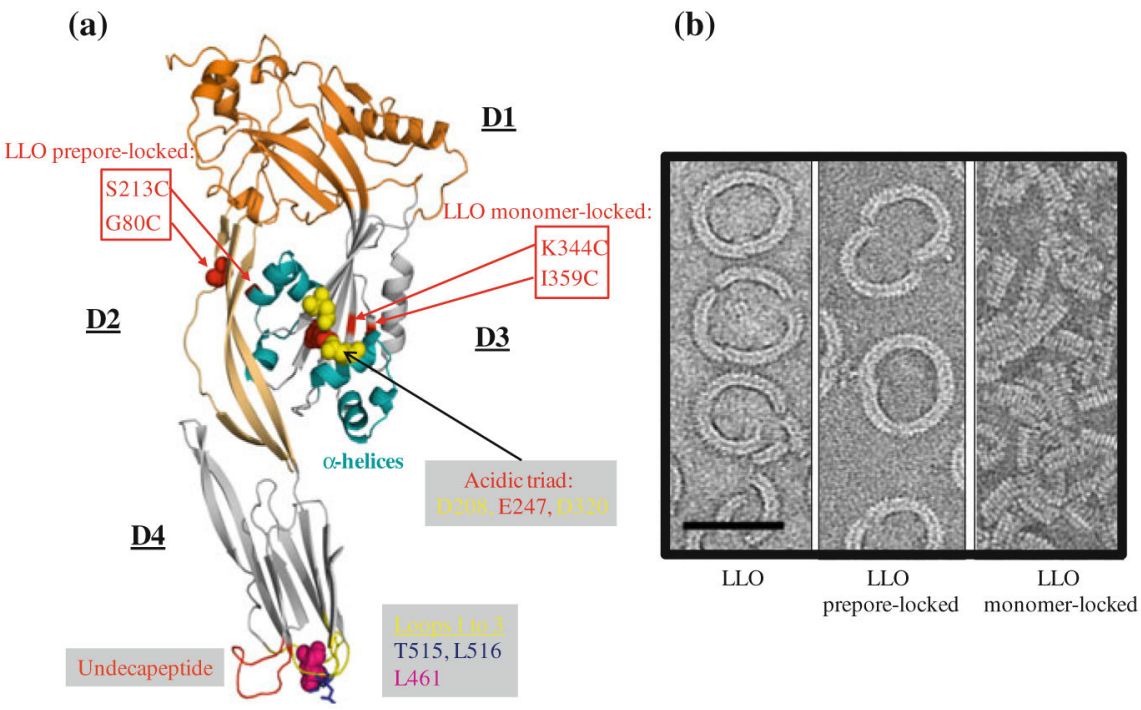

Fig. 9.2.

Model for LLO pore formation. a Model for LLO ribbon structure based upon PFO crystal structure (PBD\#1PFO) generated with Pymol [69]. LLO, similar to other CDCs, is thought to be organized into four domains (D1-D4). D4 is involved in binding to the lipid bilayer through three hydrophobic loops (L1-L3) located at the base of D4. L1 contains the cholesterol-binding motif T515/L516. Leucine 461 controls the LLO oligomerization rate. The undecapeptide sequence, which contains the unique cysteine, controls conformational remodeling in D3 during toxin oligomerization. The $\alpha$-helices in D3 convert into two $\beta$ strands per monomer to form the $\beta$ barrel pore. The acidic triad in D3 is responsible for LLO denaturation at neutral $\mathrm{pH}$ (at the temperature of the host). Amino acid substitutions in LLO monomer-locked and LLO preporelocked variants are indicated by the red boxes. Dr. Eusondia Arnett (Ohio State University, USA) helped designing the LLO model. b Transmission electron microscopy of the LLO pore formed on lipid droplets. The images represent oligomers of native LLO, LLO prepore-locked, and LLO monomer-locked variants (scale bar $=50 \mathrm{~nm}$ ) [89]. The transmission electron microscopy images were captured by Dr. Elisabeth M. Wilson-Kubalek (The Scripps Research Institute, USA) 


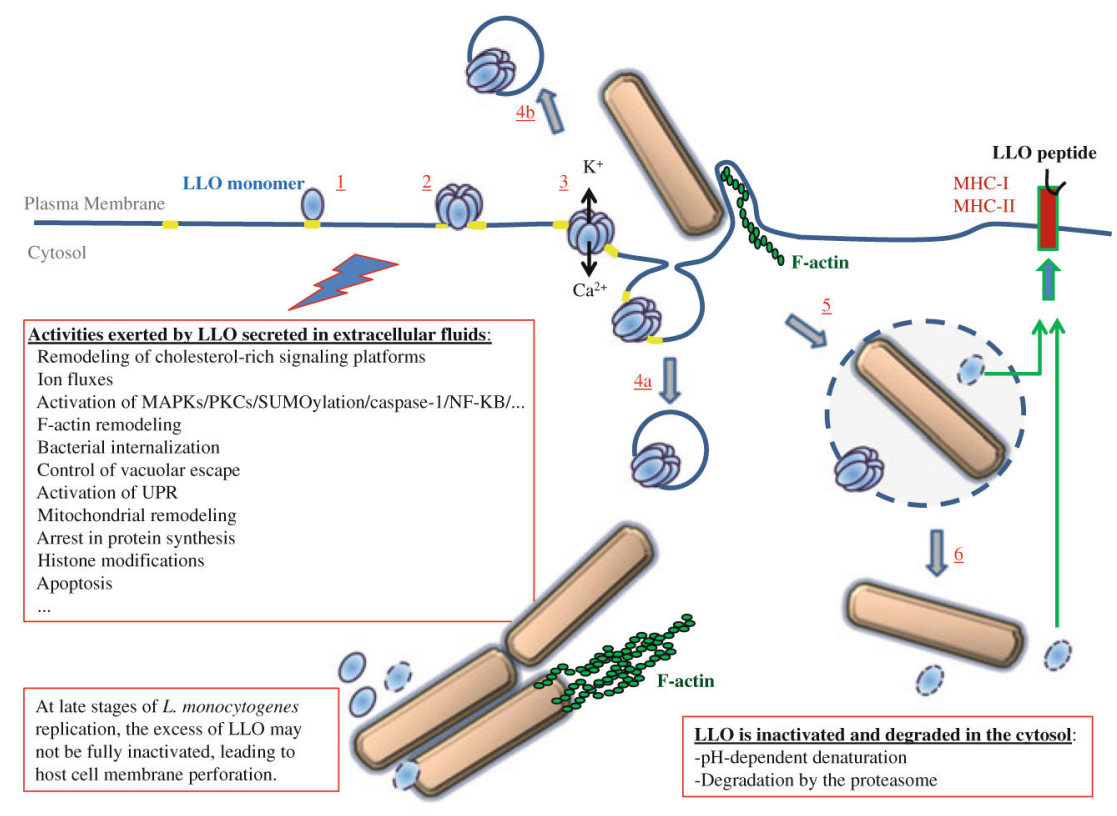

Fig. 9.3.

Model for the multifaceted activity of LLO during the L. monocytogenes intracellular lifecycle. LLO is secreted as a water-soluble monomer that binds to cholesterol in the host plasma membrane (1). The toxin assembles into a prepore complex (2), which then vertically collapses to form the transmembrane pore, leading to rapid fluxes of ions and small molecules (3). It is proposed that LLO interaction with and remodeling of lipid raft signaling platforms (in yellow), and fluxes of ions and molecules across the LLO pore complex, activate multiple signaling pathways. Downstream events include plasma membrane repair, which may involve the internalization $(4 a)$ and/or extrusion $(4 b)$ of LLO vesicles; F-actin remodeling and activation of the endocytic uptake of the bacterium (5). Also, signaling initiated by LLO at the plasma membrane may influence vacuolar escape (6). Independently of bacterial internalization, extracellular LLO exerts multiple effects on target cells including modifications of ER and mitochondria; protein synthesis; histone modifications; and apoptosis. The signaling activities of LLO though activation of transcription factors and histone modifications affect the production of inflammatory mediators; however, it is not always clear whether LLO exerts a pro- or anti-inflammatory function. LLO produced in the primary and secondary (not shown in the figure) vacuoles release the bacterium into the cytosol. Once LLO is produced in the cytosol, several mechanisms decrease its activity and production. Nevertheless, at late stages of intracellular replication, when the number of bacteria is very high, an excess of LLO may not be efficiently inactivated leading to cell damage. Finally, digestion of LLO in the phagosome or cytosol generates peptides for presentation by Class II or I MHC molecules, activating the adaptive immune response 